\title{
Documentación
}

CIUDAD Y TERRITORIO

ESTUDIOS TERRITORIALES

ISSN(P): 2697-231X; ISSN(E): 2697-2328

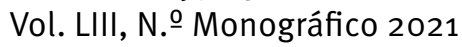

Págs. 239-276

https://doi.org/10.37230/CyTET.2021.M21.14.1

CC BY-NC-ND

\section{La Estrategia de Rehabilitación ERESEE 2020: una oportunidad para un cambio de modelo en el sector de la vivienda en España}

Eduardo de SAnTIAgo-RodrígueZ

Consejero Técnico - Subdirección de Políticas Urbanas, MITMA

RESUMEN: La Estrategia a largo plazo para la Rehabilitación Energética en el Sector de la Edificación en España (ERESEE) 2020 es un documento estratégico que, de acuerdo con la obligación establecida en la Directiva 2010/31/UE, pretende impulsar una transformación profunda del sector de la edificación para alinearlo con los objetivos generales en materia de energía y clima establecidos a medio y largo plazo, tomando como respectivos horizontes los años 2030 y 2050 . En este artículo se presentan sus principales contenidos. Se comienza repasando el diagnóstico del parque residencial español y del consumo energético en las viviendas. A continuación, se aborda la modelización del parque, presentando la metodología y los principales resultados, a partir de los cuales se plantean una serie de enfoques de rehabilitación que incluyen intervenciones sobre la envolvente y las instalaciones de calefacción y ACS, calculándose los costes económicos asociados y los ahorros de energía y emisiones obtenidos. Se presentan también diversos escenarios, cuantificándose las inversiones necesarias para su desarrollo y sus principales resultados desde el punto ambiental (ahorros de energía y emisiones), micro y macroeconómico. Finalmente, se enuncian las principales medidas planteadas por la ERESEE y se concluye reflexionando sobre la necesidad de articularlas desde un punto de vista integrado y multiescalar.

PALABRAS CLAVE: Rehabilitación energética; Energía y clima; Sector Edificación; Financiación; Vivienda.

\section{The ERESEE 2020 Rehabilitation Strategy: an opportunity for a model change in the Spanish housing sector}

ABSTRACT: The long-term Energy Renovation Strategy for the Building Sector in Spain (ERESEE) 2020 is a strategic document that, in accordance with the obligation established in Directive 2010/31/EU,

Correo electrónico: edesantiago@mitma.es; N.o ORCID: https://orcid.org/0000-0002-1867-7867 
aims to promote a profound transformation of the Spanish building sector in order to align it with the general objectives in terms of energy and climate established in the medium and long term for 2030 and 2050. This paper presents its main contents. It begins by reviewing the diagnosis of the Spanish residential stock and its energy consumption. Next, the stock modeling is approached, presenting the methodology and the main results, from which a series of rehabilitation approaches are proposed, including interventions on the building envelope and on the Heating and DHW systems, calculating the associated economic costs and the energy and emission savings obtained. Various scenarios are also presented, quantifying the investments necessary for their development and the main results from the environmental point of view (energy savings and emissions), and the micro and macroeconomic perspective. Finally, the main measures proposed by the ERESEE are enunciated, concluding with a reflection on the need to articulate them from an integrated and multiscalar point of view.

Keywords: Energy renovation; Energy and Climate; Building Sector; Financing; Housing.

“El Acuerdo de París de 2015 sobre Cambio Climático resultante de la $21^{\underline{a}}$ Conferencia de las Partes en la Convención Marco de las Naciones Unidas sobre el Cambio Climático (COP 21) impulsa los esfuerzos de la Unión para descarbonizar su parque inmobiliario. Teniendo en cuenta que casi el $50 \%$ del consumo de energía final de la Unión se destina a calefacción y refrigeración, de la cual el $80 \%$ se consume en edificios, la consecución de los objetivos de la Unión en materia de energía y cambio climático está relacionada con los esfuerzos de la Unión para renovar su parque inmobiliario priorizando la eficiencia energética, aplicando el principio "primero, la eficiencia energética» y estudiando el despliegue de las energías renovables".

Directiva (UE) 2018/844 del Parlamento Europeo y del Consejo, de 30 de mayo de 2018, por la que se modifican la Directiva 2010/31/UE relativa a la eficiencia energética de los edificios y la Directiva 2012/27/UE relativa a la eficiencia energética.

\section{Contexto y marco legal: la apuesta de la Unión Europea por la eficiencia energética}

- I texto más arriba reproducido, recoge de forma íntegra el considerando 7 de la Directiva (UE) 2018/844 del Parlamento Europeo y del Consejo, de 30 de mayo de 2018, por la que se modifican la Directiva 2010/31/UE relativa a la eficiencia energética de los edificios y la Directiva 2012/27/UE relativa a la eficiencia energética. Mediante esta

\footnotetext{
1 Accesible en:

http://www.fomento.gob.es/MFOM/LANG CASTELLANO/ PLANES/ELPRESEEESP/

2 Accesible en:
}

Directiva 2018/844, las disposiciones relativas a las Estrategias de Renovación a largo plazo, establecidas hasta ese momento en la Directiva 2012/27/UE de eficiencia energética, debian trasladarse a la Directiva 2010/31/UE, de eficiencia energética de los edificios, donde se integran a partir de ahora de forma más coherente en un nuevo artículo 2.bis.

España dio cumplimiento al primer mandato recogido entonces en el artículo 4 de la Directiva 2012/27/UE, mediante la elaboración — por parte del Ministerio de Fomento- de la "Estrategia a largo plazo para la Rehabilitación Energética en el Sector de la Edificación en España (en adelante ERESEE) 2014"'. Posteriormente, y siguiendo la obligación establecida en el mismo artículo de revisar las Estrategias nacionales cada 3 años, el Ministerio de Fomento, lideró el desarrollo de la ERESEE $2017^{2}$, presentada a la Comisión Europea en el marco de los Planes Nacionales de Acción para la Eficiencia Energética (PNAEE), coincidiendo con la revisión que también se hizo en 2017 del PNAEE 2014-2020.

Estas dos estrategias fueron muy bien valoradas por el Joint Research Centre (JRC) en su Informe de Evaluación de las Estrategias nacionales encargado por la DG Energy de Comisión Europea. El informe relativo a la primera versión de la Estrategia presentada por cada Estado Miembro en 2014 fue publicado en 2016 (CASTELLAZZI, L. \& al., 2016), otorgando a la ERESEE 2014 española la mayor puntuación de entre las 31 Estrategias presentadas; y el segundo, publicado en 2019 (CASTELLAZZI L. \& al., 2019) volvía 
a valorar con la máxima puntuación la ERESEE 2017, esta vez empatada con la francesa.

La apuesta por la rehabilitación energética del parque edificado de los Estados Miembros es cada vez más fuerte y decidida por parte de la Comisión Europea, lo que se ve reflejado en el "Green Deal" o "Pacto Verde" que la Comisión Europea presentó a principios de $2020^{3}$, en la "Gran Ola de la Renovación" o "Renovation Wave"4, así como en las propuestas sobre el Plan de Recuperación post Covid-19 "Recovery and Resilience Facility"s. Esta ambición también tiene su reflejo en la ampliación del contenido y concreción que deben tener las Estrategias nacionales de Renovación a largo plazo, recogido, tras la publicación de la Directiva 2018/844/UE, en el artículo 2 bis de la Directiva 2010/31/UE.

En concreto, esta ampliación de contenido supone, como novedad, introducir, entre otras, las siguientes cuestiones: políticas y acciones destinadas a todos los edificios públicos, el establecimiento de una hoja de ruta con medidas e indicadores de progreso mesurables establecidos nacionalmente, abordar el problema de la Pobreza Energética y finalmente, realizar un proceso de participación pública que permita recoger la visión de los distintos sectores que juegan un papel decisivo para que la renovación energética de los edificios, en la intensidad y en los ratios deseables, sean una realidad.

\section{El proceso de participación pública}

De acuerdo con la exigencia de la Directiva, se llevó a cabo un proceso de participación pública para contribuir a la redacción de la ERESEE $2020^{6}$. Este proceso fue liderado por el Ministerio de Transportes, Movilidad y Agenda Urbana (MITMA), coordinador de la elaboración de ésta, y tuvo lugar entre septiembre y diciembre de 2019, contando con la participación de GBCe como coordinador de las jornadas y facilitador.

En el proceso se empleó la metodología de trabajo que se había desarrollado previamente en el proyecto europeo BUILD UPON ${ }^{7}$, también coordinado por GBCe y que tuvo como objetivo la coordinación y el apoyo a la redacción de las revisiones de las Estrategias de Rehabilitación a largo plazo para 2017 en 13 países europeos. Así mismo se partió de los resultados ya obtenidos por este proyecto, identificándose, en primer lugar, en un mapa de agentes, a los actores implicados en la rehabilitación en España, así como los conocimientos e iniciativas emergentes que podían enriquecer la revisión de la Estrategia.

Posteriormente se inició un proceso de debate y diseño colectivo mediante una serie de mesas dinámicas de discusión en las que todos los participantes pudieron compartir y contrastar sus opiniones. Se llevaron a cabo 6 jornadas en torno a los temas identificados como clave para el éxito de la Estrategia y una final de presentación de resultados: Jornada Inaugural (11/10/2019), Jornada sobre Financiación y Modelo de Negocio (15/10/2019), Jornada sobre el Vector Energético de la Edificación (24/10/2019), Jornada Ayuntamientos y la Gestión de la Rehabilitación (28/10/2019), Jornada sobre Comunicación, Capacitación y Profesionalización (30/10/2019), Jornada Final de Presentación de Conclusiones (10/12/2019), celebrada en el marco de la COP25 de Madrid.

En total, más de 200 agentes representantes de toda la cadena de valor de la rehabilitación participaron en estos debates, a los que también asistieron representantes de las Administraciones Públicas involucradas en la redacción e implantación de la Estrategia. Este proceso ha ido más allá de recoger las opiniones de las entidades civiles y ha servido de punto de encuentro entre los diferentes actores de la rehabilitación, buscando soluciones comunes y creando una comunidad de diálogo, que se ofreció para seguir trabajando para facilitar la implantación de la Estrategia (FIG. 1).

De esta forma se ha conseguido un doble objetivo: recabar el conocimiento y la opinión del sector para la revisión de la Estrategia y dinamizar las sinergias entre los diferentes actores implicados para mejorar la colaboración. Todo ello con el objetivo final de revisar, mejorar y adaptar la Estrategia a la realidad de la edificación española.

\footnotetext{
${ }^{3}$ https://ec.europa.eu/info/strategy/priorities-2019-2024/european-green-deal es

${ }^{4}$ https://ec.europa.eu/energy/topics/energy-efficiency/energy-efficient-buildings/renovation-wave en

${ }^{5}$ https://ec.europa.eu/info/business-economy-euro/recoverycoronavirus/recovery-and-resilience-facility en
}

${ }^{6}$ https://www.mitma.gob.es/el-ministerio/planes-estrategicos/ estrategia-a-largo-plazo-para-la-rehabilitacion-energetica-enel-sector-de-la-edificacion-en-espana

7 https://gbce.es/blog/proyecto/build-upon/ 
Los resultados y propuestas surgidas en este proceso se recogieron en el Documento de Observaciones y Propuestas $^{8}$, y se entregaron al Ministerio de Transporte, Movilidad y Agenda Urbana para su consideración.

El proceso participativo y su metodología están descritos con detalle en el Informe del proceso de participación pública, el resto de recursos

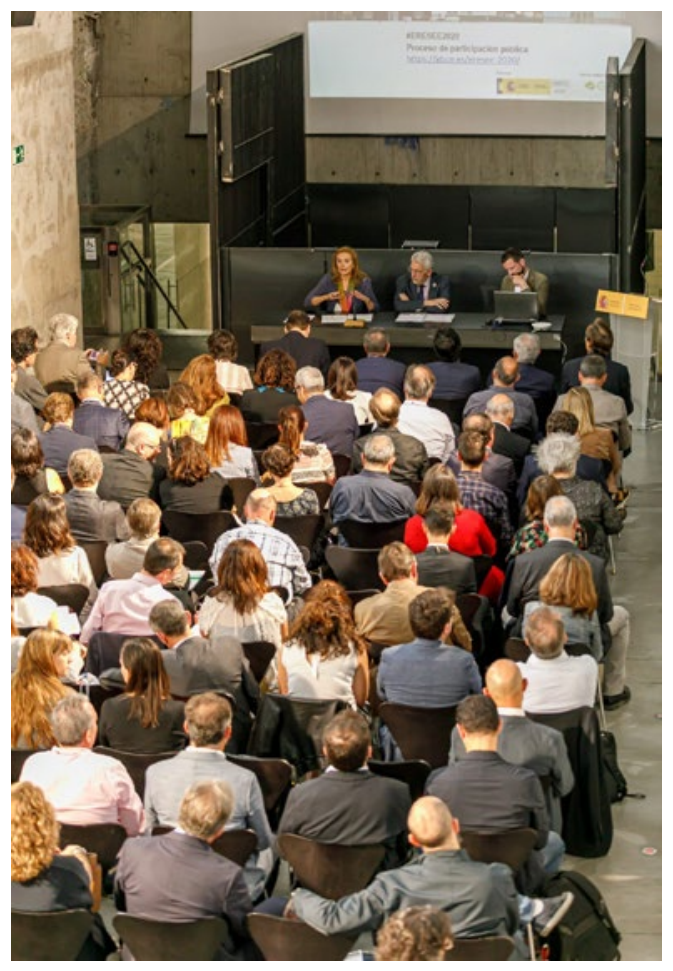

FIG. 1/ Imágenes del proceso de participación.

Fuente: GBCe.

\footnotetext{
${ }^{8}$ GBCe (2020): Presentación de conclusiones del proceso participativo \#ERESEE2020 Documento de observaciones y propuestas resultantes del proceso de participación pública para la actualización de la Estrategia a largo plazo para la Rehabilitación Energética en el Sector de la Edificación en España (ERESEE 2020).

https://gbce.es/wp-content/uploads/2020/06/Procesoparticipativo-ERESEE2020 Conclusiones-Obs-y-Prop.pdf ${ }_{9}$ https://gbce.es/eresee-2020/

10 https://www.miteco.gob.es/es/transicion-justa/default.aspx ${ }_{11}$ Enviado el 31 de marzo de 2020 a la Comisión Europea y actualmente en fase de consulta pública del Estudio Ambiental Estratégico (EAE) del plan y que ya fue remitido a Bruselas el pasado mes de enero, como borrador actualizado. Con esta nueva comunicación a la Comisión Europea, España da cumplimiento al Reglamento (UE) 2018/1999 del Parlamento Europeo y del Consejo de 11 de diciembre de 2018 sobre la gobernanza de la Unión de la Energía y de la Acción por el Clima.
}

generados (vídeos resumen de las sesiones, mapa de actores, mapa de iniciativas, etc.) están publicados en la web de $\mathrm{GBCe}^{9}$.

\section{Objetivos a 2030 y a 2050 en coordinación con otros documentos estratégicos}

La ERESEE 2020 se configura como el instrumento que desarrolla en detalle la visión estratégica a largo plazo del sector de la edificación de manera articulada con el resto de documentos sobre energía y clima aprobados recientemente por el Gobierno de España.

Entre ellos, cabe destacar el Marco Estratégico de Energía y Clima, planteado en respuesta al Acuerdo de París de 2015 y la Agenda 2030 de Desarrollo Sostenible de Naciones Unidas, como puntos de partida de una nueva agenda global sostenible que conlleve la transformación del modelo económico y de un nuevo contrato social de prosperidad inclusiva dentro de los límites del planeta. En España, este Marco está formado por 3 documentos clave, con los que se alinea la ERESEE 2020: el Proyecto de Ley de Cambio Climático y Transición Energética, la Estrategia de Transición Justa ${ }^{10}$, y el Plan Nacional Integrado de Energía y Clima 2021203011 (PNIEC 2030).

Además, este marco se completa con otros documentos como la Agenda Urbana Española ${ }^{12}$, la Estrategia de Pobreza Energética 2019-2024 ${ }^{13}$, el Plan Nacional de Adaptación al Cambio Climático 2021-2030 ${ }^{14}$, la Estrategia Española de Economía Circular ${ }^{15}$, y finalmente, con la Estrategia a Largo Plazo para una Economía Española Moderna, Competitiva y Climáticamente Neutra en $2050^{16}$ (ELP 2050).

https://www.miteco.gob.es/images/es/pnieccompleto tcm30508410.pdf

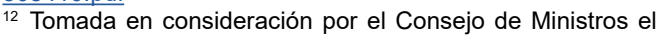
22 de febrero de 2019: https://www.aue.gob.es/

${ }^{13}$ Aprobada por el Consejo de Ministros el 05/04/2019: https://www.miteco.gob.es/es/prensa/estrategianacionalcontralapobrezaenergetica2019-2024 tcm30-496282.pdf

${ }^{14}$ Aprobado por el Consejo de Ministros el 22 de septiembre de 2020: https://www. miteco.gob.es/es/cambio-climatico/temas/impactos-vulnerabilidad-y-adaptacion/pnacc2021-2030 tcm30-512163.pdf

${ }^{15}$ Denominada España Circular 2030. Fue aprobada por el Consejo de Ministros el Consejo de Ministros el 02/06/2020: https://www.miteco.gob.es/es/prensa/200602npestrategiadee conomiacircularfinalpdf tcm30-509537.pdf

${ }^{16}$ Aprobada por el Consejo de Ministros de 03/11/2020. https://www.miteco.gob.es/es/prensa/documentoelp tcm30516109.pdf 
La ELP 2050 es la hoja de ruta estratégica para la descarbonización en España, planteando como objetivo que, antes de 2050, España reduzca sus emisiones de Gases de Efecto Invernadero (GEI) en un $90 \%$ respecto a los niveles de 1990. Esto implica alcanzar la neutralidad climática en ese horizonte mediante la reducción de las emisiones de $\mathrm{CO}_{2}$ desde 334 millones de toneladas equivalentes $\left(\mathrm{MtCO}_{2} \mathrm{eq}\right)$ emitidas en 2018 a un máximo de $29 \mathrm{MtCO}_{2} \mathrm{eq}$ emitidas en 2050 , siendo el $10 \%$ restante de las emisiones absorbido por los sumideros de carbono, que serán capaces de captar unas 37 $\mathrm{MtCO}_{2}$ eq a mediados de siglo.

Para conseguir este ambicioso objetivo será necesario combinar el ahorro y la eficiencia energética primero ${ }^{17}$, con el impulso de las energías renovables. La ELP 2050 propone que, mediante la mejora de la eficiencia energética y el

Consumo de energía final en el sector residencial (excluidos usos no energéticos) para el Escenario Objetivo ELP (GWh)

\begin{tabular}{lcccc} 
& $\mathbf{2 0 2 0}$ & $\mathbf{2 0 3 0}$ & $\mathbf{2 0 4 0}$ & $\mathbf{2 0 5 0}$ \\
\hline Fósiles & 72.448 & 47.465 & 21.995 & - \\
\hline Electricidad & 68.823 & 64.403 & 78.561 & 88.110 \\
\hline Energías renovables & 31.148 & 34.157 & 23.627 & 20.155 \\
\hline Total & 172.419 & 146.025 & 124.172 & 108.264
\end{tabular}

Ahorros de energía final en el sector residencial (excluidos usos no energéticos) para el Escenario Objetivo ELP (GWh)

\begin{tabular}{lcccc} 
& $\mathbf{2 0 2 0 - 2 0 3 0}$ & $\mathbf{2 0 3 0 - 2 0 4 0}$ & $\mathbf{2 0 4 0 - 2 0 5 0}$ & $\mathbf{2 0 2 0 - 2 0 5 0}$ \\
\hline Fósiles & -24.983 & -25.470 & -21.995 & -72.448 \\
\hline Electricidad & -4.420 & 14.159 & 9.548 & 19.287 \\
\hline Energías renovables & 3.009 & -10.530 & -3.472 & -10.993 \\
\hline Total & -26.394 & -21.853 & -15.907 & -64.154 \\
\hline
\end{tabular}

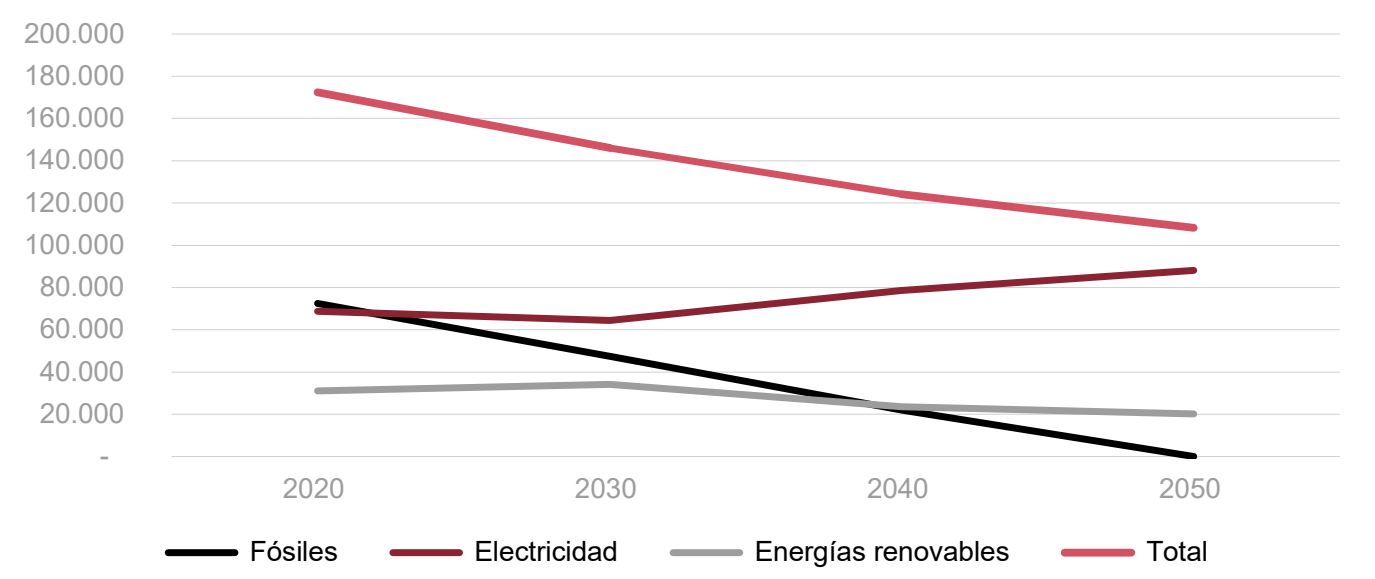

Nota: Fósiles: engloba Carbón, Gasóleo, GLP y Gas Natural. Electricidad: incluye toda la energía eléctrica, incluso la de origen renovable (eólica, hidroeléctrica, etc.). Energías Renovables (excepto electricidad): incluye Biomasa Leña, Biomasa Pellets, Solar, Geotermia.

FIG. 2/ Resumen de consumos de energía final y ahorros en el sector residencial para el Escenario Objetivo de la ELP 2050.

\footnotetext{
${ }^{17}$ Lo que se conoce con el principio de "Energy Efficieny First".
} 
ahorro, el consumo de energía primaria se reduzca en torno a un $50 \%$ desde el año 2020 hasta el año 2050. En el sector residencial, este objetivo general se traduce en la reducción del consumo de energía en 2050 en más del $30 \%$ sobre el actual, lo que significa reducir unos $64.000 \mathrm{GWh}$.

En cuanto a las energías renovables, se tiende a una electrificación del sistema, fundamentalmente basada además en energías renovables, que representarán el $97 \%$ del consumo final. En el sector de la edificación, el objetivo básico en 2050 es avanzar hacia la electrificación en paralelo a la eliminación de los combustibles fósiles, en particular del Gas Natural, que en la actualidad es uno de los más importantes.

Todas estas transformaciones señaladas generarán un cambio en la estructura energética, que redundará en una considerable reducción de la dependencia exterior. Se estima que España pasará de importar el $73 \%$ de la energía consumida en 2018 al $13 \%$ en 2050 , lo que implicará un ahorro acumulado en importaciones de combustibles fósiles entre 2021 y 2050 estimado en 344.000 millones de euros.

En la FIG. 2 se resumen los objetivos - para todos los usos: calefacción, ACS, iluminación, cocinas, etc.- de consumo de energía final ${ }^{18}$ en el sector residencial, de acuerdo con la ELP 2050.

En cuanto a los objetivos intermedios a 2030 , estos vienen fijados en el Plan Nacional Integrado de Energía y Clima (PNIEC 2030), que plantea una reducción de un $23 \%$ de emisiones de gases de efecto invernadero respecto a 1990. Este objetivo de reducción implica eliminar una de cada tres toneladas de (GEI) gases de efecto invernadero que se emiten actualmente. Se trata de un esfuerzo coherente con el incremento de la ambición a nivel europeo para 2030, así como con el Acuerdo de París.

En el sector de la edificación residencial, estos objetivos energéticos para el periodo 20202030 se traducen en: a) la rehabilitación de la envolvente de 1,2 millones de viviendas, con un ahorro acumulado de energía final durante el periodo de casi 800 ktep y una inversión total estimada de $10.223 \mathrm{M} € ; \mathrm{y}, \mathrm{b})$ la mejora de la eficiencia de más de 3,5 millones de instalaciones de climatización y ACS (1 millón de

18 Nótese que la electricidad de origen renovable está incluida en esta tabla en "Electricidad" y no en "Energías renovables". En realidad, en 2050 se prevé que casi todo el consumo eléctrico sea también renovable.

${ }^{19}$ Lo mismo ocurre en términos de consumo unitario por $\mathrm{m}^{2}$ de energía en edificios residenciales, siendo el consumo en instalaciones centralizadas y 2,65 millones de instalaciones individuales), con un ahorro acumulado de energía final de casi 4.000 ktep y una inversión total estimada de más de 12.208 M€.

En términos de vectores energéticos, los objetivos a 2030 son los siguientes:

- La eliminación del carbón como fuente de energía en el sector residencial y la reducción al máximo posible de los GLP (Gases Licuados del Petróleo) y del Gasóleo.

- La mejora de la eficiencia en los sistemas de calefacción que utilizan biomasa, reduciendo especialmente el consumo de leña, que es muy ineficiente en la actualidad.

- Incremento moderado de la electricidad, iniciando la progresiva introducción de la Bomba de Calor de forma selectiva.

- Incremento significativo en términos porcentuales de la energía Solar Térmica, con especial atención al autoconsumo.

\section{Análisis de la distribución del parque edificado y del consumo de energía en España}

Entre los retos estructurales más importantes señalados por la ERESEE 2020, pero que ya estaban presentes en la ERESEE 2017, se encuentran las condiciones climáticas españolas. En efecto, la relativa benignidad del clima español en comparación con el de otros países del centro o el norte de Europa, hace que el consumo medio por hogar sea mucho menor ${ }^{19}$ y que, por tanto, también lo sean las posibilidades de capitalización de los ahorros energéticos, principal instrumento de financiación de la rehabilitación tal y como plantea la Directiva 2010/31 UE. Por el contrario, la refrigeración, que -a veces se piensa que podría compensar estas diferencias- en realidad apenas supone un $1 \%$ del consumo doméstico.

Además, dentro de España, las condiciones climáticas son muy diferentes entre unas zonas y otras. La ERESEE 2020 realiza un análisis detallado del número de viviendas y del consumo según las zonas climáticas del Código Técnico

España $\left(103,04 \mathrm{kWh} / \mathrm{m}^{2}\right)$ de los más bajos de Europa, frente a los $184,14 \mathrm{kWh} / \mathrm{m}^{2}$ de media en la EU28, o los 308,09 $\mathrm{kWh} / \mathrm{m}^{2}$ de Rumanía. Fuente: Comisión Europea (2016). https://ec.europa.eu/energy/en/eu-buildings-factsheets 
de la Edificación (CTE), cuyos resultados principales se recogen en la FIG. 3.

La conclusión es que el consumo medio de energía para climatización y ACS por vivienda varía de forma drástica en función de la zona

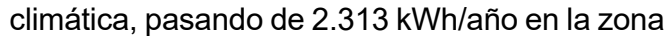
A (más cálida), a 11.504 kWh/año en la zona $\mathrm{E}$ (más fría). Esto determina que zonas climáticas con análogo número de edificios (como, por ejemplo, la B y la D) tengan consumos globales muy diferentes, siendo el consumo en la zona D más del doble del correspondiente a la zona B. Al mismo tiempo, los consumos también son muy diferentes en función de las tipologías de vivienda (unifamiliar, colectiva de menos de 3 plantas de altura, colectiva en bloques de más de 3 alturas, etc.). Siendo las inversiones en cada tipología de vivienda prácticamente idénticas en cada zona climática ${ }^{20}$, el colofón que se deriva de este análisis es que no puede hablarse de una rentabilidad media de la rehabilitación energética y que, por tanto, será necesario focalizar las intervenciones en determinadas zonas y tipologías.

\section{Modelización del parque residencial español y de su consumo energético: Metodología y principales resultados}

Dada la necesidad de este análisis segmentado del parque residencial y de sus consumos, la ERESEE 2020 realiza una modelización del mismo, que parte de la definición de una serie de variables que tienen un peso determinante en el análisis del comportamiento energético de la edificación, y que son las siguientes:

- Tipología de vivienda (3 tipos): unifamiliar $(U)$; colectiva hasta 3 plantas (C); colectiva en bloques de más de 3 plantas (B).

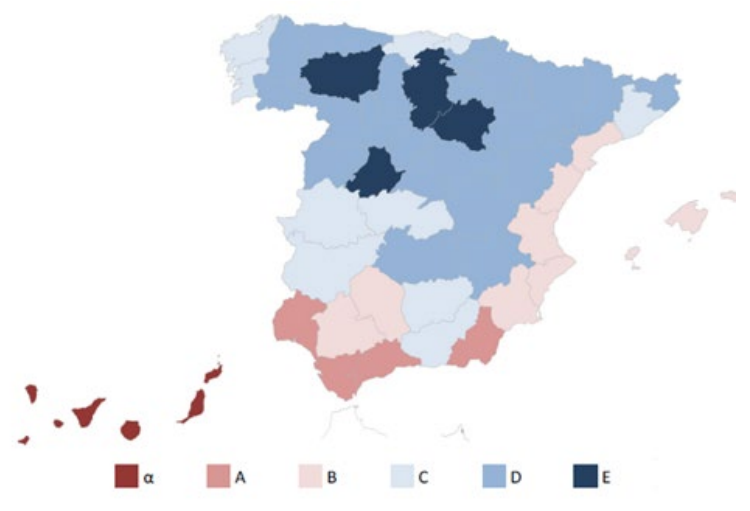

\begin{tabular}{lrrrrr}
\hline & $\begin{array}{c}\text { Suma de } \\
\text { No viviendas }\end{array}$ & \multicolumn{1}{c}{$\%$} & $\begin{array}{c}\text { Suma de Consumo } \\
\text { por caso } \\
\text {-KWh/caso・año- }\end{array}$ & \% & \multicolumn{1}{c}{$\begin{array}{c}\text { POR VIVIENDA } \\
\text { KWh/año }\end{array}$} \\
\hline Zona Climática A & 1.373 .589 & 8,3 & 3.178 .158 .585 & 4,1 & $2.313,8$ \\
\hline Zona Climática B & 4.464 .174 & 26,9 & 12.540 .374 .734 & 16,1 & $2.809,1$ \\
\hline Zona Climática C & 5.837 .386 & 35,2 & 27.194 .364 .262 & 34,9 & $4.658,7$ \\
\hline Zona Climática D & 4.519 .052 & 27,2 & 30.406 .247 .636 & 39,0 & $6.728,5$ \\
\hline Zona Climática E & 403.926 & 2,4 & 4.647 .018 .904 & 6,0 & $11.504,6$ \\
\hline Total general & 16.598 .127 & 100,0 & 77.966 .164 .120 & 100,0 & $4.697,3$ \\
\hline
\end{tabular}

FIG. 3/ Mapa de zonas climáticas españolas según el CTE y distribución en ellas de las viviendas.

\footnotetext{
${ }^{20}$ Ya que sólo dependen de la superficie, que es un factor independiente del clima.
} 
- Periodo de construcción (7 períodos) $)^{21}$ : hasta 1900; 1901 a 1940; 1941 a 1960; 1961 a 1980; 1981 a 2007; 2008 a 2020; desde 2021.

- Tamaño del municipio (2 grupos): rural $(<20.000)$, urbano $(>20.000)$.

- Provincia (50 provincias): P01 a P50. La desagregación a nivel provincial es la que permite posteriormente la agrupación por CCAA o por zonas climáticas del Código Técnico de la Edificación, asignando a toda la provincia la zona de la capital.

- Tecnología de calefacción (9 tecnologías): Caldera o calentador de GLP; Estufas, braseros, chimeneas de GLP; Caldera o calentador de Gasoil; Caldera o calentador de Gas natural; Convector de Gas natural; Caldera o calentador de Biomasa; Estufas, braseros, chimeneas de Biomasa; Bomba de calor aerotérmica de Electricidad; Caldera o calentador de Electricidad.

- Situación de pobreza energética (2 casos): sí; no.

El cruce de estas variables arroja un total de unos 37.800 casos diferentes, con los que se modeliza el parque residencial español, permitiendo trabajar de forma desagregada o agregada en diferentes grupos de casos, denominados clústeres ${ }^{22}$. Los clústeres tipológicos resultantes del cruce de las variables tipología y fecha de construcción son los 15 siguientes que pueden verse en la FIG. 4.

Cada uno de estos clústeres se ha modelizado volumétricamente (DE SANTIAGO, 2019), obteniéndose los parámetros de superficie de envolvente, $\mathrm{m}^{2}$ de fachada opaca, $\mathrm{m}^{2}$ de medianera adiabática, $\mathrm{m}^{2}$ de huecos en fachada, etc., que se pueden ver en la FIG. 5 a modo de ejemplo para 3 de los 15 clústeres.

La distribución de las viviendas principales españolas por clústeres resulta ser la que puede verse en la FIG. 6.

${ }^{21}$ Estos períodos se justifican en base a los cambios técnicos o normativos que determinan los sistemas constructivos característicos de cada uno de ellos: antes de 1940 (edificación tradicional), entre 1940 y 1960 (primer ciclo de expansión urbana con tipologías de bloques), entre 1960 y 1980 (segundo ciclo de expansión urbana con cambios en los sistemas constructivos), entre 1980 y 2007 (nuevos cambios técnicos y periodo de aplicación de la NBE-CT/79 que demandaba un mínimo de aislamiento térmico en los cerramientos), a partir de 2008 (implementación del Código Técnico de la Edificación CTE que exige condiciones de eficiencia energética al edificio), desde 2021 Edificios de Consumo de Energía Casi Nula. Esta segmentación ha permitido -asignando los sistemas constructivos dominantes de cada época en cada clústerinferir el grado de aislamiento de los cerramientos.
Una vez se tienen modelizadas geométricamente las viviendas de los clústeres, se procede a caracterizar técnicamente sus cerramientos (fachadas, cubiertas, forjados de planta baja, y huecos) dado que se supone que cada clúster tiene unas características constructivas similares. Para cada uno de estos elementos de la envolvente (fachadas, cubiertas, forjados de planta baja, y huecos) se dispone de una tabla que asigna los porcentajes para cada clúster de las diferentes soluciones constructivas que pueden presentarse. Por ejemplo, para las fachadas se consideran: Muro de 1 hoja macizo grueso (1 pie), Muro de 1 hoja macizo grueso (1 pie y medio), Muro de 1 hoja sin cámara y sin aislamiento, Muro de 2 hojas con cámara

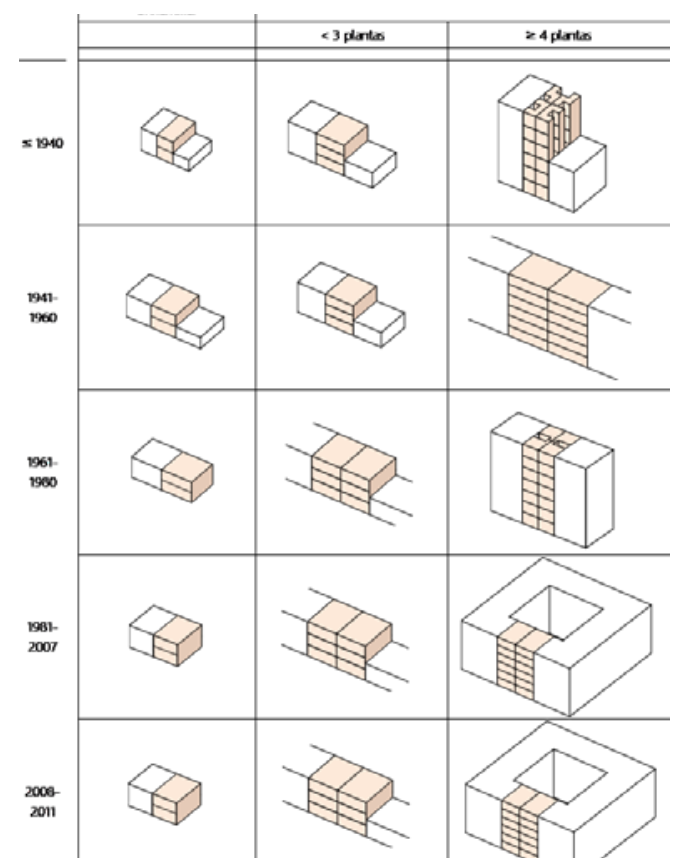

FIG. 4/ Matriz de los clústeres tipológicos de vivienda considerados en la ERESEE 2020.

Fuente: MITMA.

${ }^{22}$ La nomenclatura que se utiliza en el documento para nombrar los grupos de casos —o clústeres - hace referencia a lo siguiente:

- Letra U, C, B: U=Viviendas Unifamiliares; C=Viviendas en edificios plurifamiliares (con 2 o más viviendas) y 3 o menos plantas; $B=$ Viviendas en edificios plurifamiliares (con 20 más viviendas) y más de 3 plantas.

- Letra mayúscula o minúscula: Mayúscula indica situación urbana (ciudades mayores de 20.000 habitantes) y minúscula, rural (ciudades menores de 20.000 habitantes). Cuando se usan las 2 letras, se refiere al clúster completo, es decir a las situaciones urbana y rural.

- < 40, 41-60, 61-80, 81-07, 08-11: Hace referencia a la edad de construcción del edificio. 
sin aislamiento, y Muro de 2 hojas con cámara con aislamiento CT79. En la tabla de la FIG. 7 se ejemplifica el caso de las fachadas (se adjunta también la correspondiente a las soluciones propuestas para los menús de intervención) para las tipologías de vivienda unifamiliar:

\begin{tabular}{|l|r|r|r|} 
Bb $<40$ \\
\hline
\end{tabular}

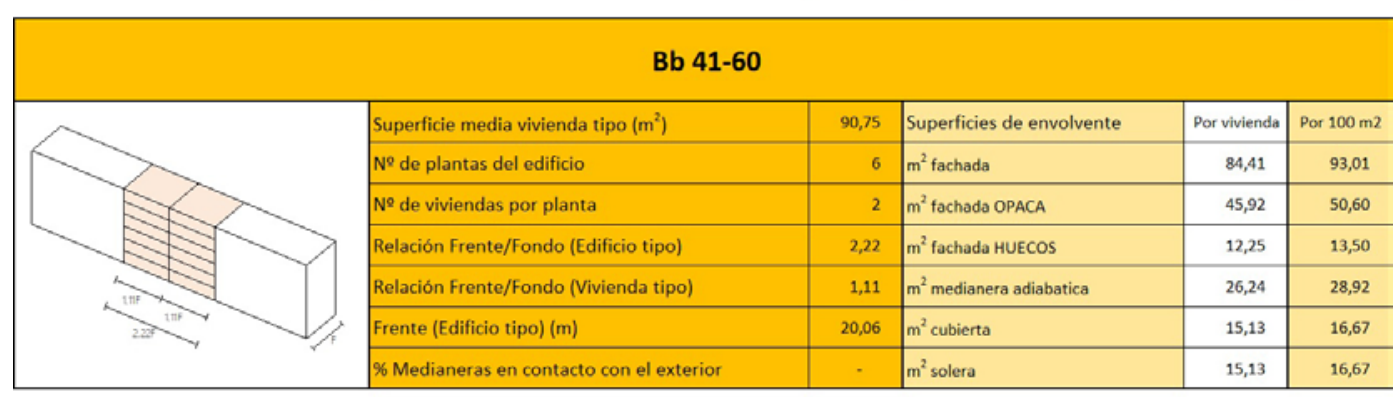

\section{Bb $61-80$}

\begin{tabular}{|c|c|c|c|c|c|}
\hline & Superficie media vivienda tipo $\left(\mathrm{m}^{2}\right)$ & 93,66 & Superficies de envolvente & Por vivienda & Por $100 \mathrm{~m} 2$ \\
\hline & N de plantas del edificio & 7 & $\mathrm{~m}^{2}$ fachada & 86,47 & 92,33 \\
\hline & № de viviendas por planta & 4 & $\mathrm{~m}^{2}$ fachado OPACA & 47,74 & 50,98 \\
\hline & Relación Frente/Fondo (Edificio tipo) & 1,16 & $\mathrm{~m}^{2}$ fachada HUECOS & 12,64 & 13,50 \\
\hline & Relación Frente/Fondo (f) vivienda (Vivienda tipo) & 1,16 & $\mathrm{~m}^{2}$ medianera adiabatica & 26,09 & 27,85 \\
\hline & Frente (Edificio tipo) (m) & 20,82 & $\mathrm{~m}^{2}$ cubierta & 13,38 & 14,29 \\
\hline $\mathrm{v}$ & $\%$ Medianeras en contacto con el exterior & - & $\mathrm{m}^{2}$ solera & 13,38 & 14,29 \\
\hline
\end{tabular}

FIG. 5/ Matriz de modelización volumétrica de los clústeres de vivienda considerados en la ERESEE 2020.

Fuente: MITMA.

\begin{tabular}{|c|c|c|c|c|}
\hline & $\begin{array}{l}\text { Uu Vivienda } \\
\text { unifamiliar }\end{array}$ & $\begin{array}{l}\text { Cc Vivienda } \\
\text { plurifamiliar } \\
\text { < } 3 \text { plantas }\end{array}$ & $\begin{array}{l}\text { Bb Vivienda } \\
\text { plurifamiliar } \\
\text { + } 3 \text { plantas }\end{array}$ & Total \\
\hline Edificio anterior a 1900 & 298.849 viv & 70.497 viv & 112.506 viv & 481.852 viv \\
\hline Edificio de 1901 a 1940 & 461.024 viv & 121.315 viv & 245.364 viv & 827.703 viv \\
\hline Edificio de 1941 a 1960 & 634.065 viv & 324.348 viv & 816.134 viv & 1.774.547 viv \\
\hline Edificio de 1961 a 1980 & 1.307.894 viv & 794.646 viv & $4.280 .881 \mathrm{viv}$ & 6.383 .421 viv \\
\hline Edificio de 1981 a 2007 & 2.963.779 viv & 1.470 .720 viv & 3.824 .103 viv & 8.258 .602 viv \\
\hline Edificio de 2008 a 2020 & 346.667 viv & 146.218 viv & 497.105 viv & 989.990 viv \\
\hline Total & 6.012 .278 & 2.927.744 & 9.776 .093 & 18.716.115 \\
\hline
\end{tabular}

FIG. 6/ Definición de Clústeres. Número de Viviendas Principales - sin Ceuta ni Melilla- según año de construcción (filas) y tipología (columnas). 

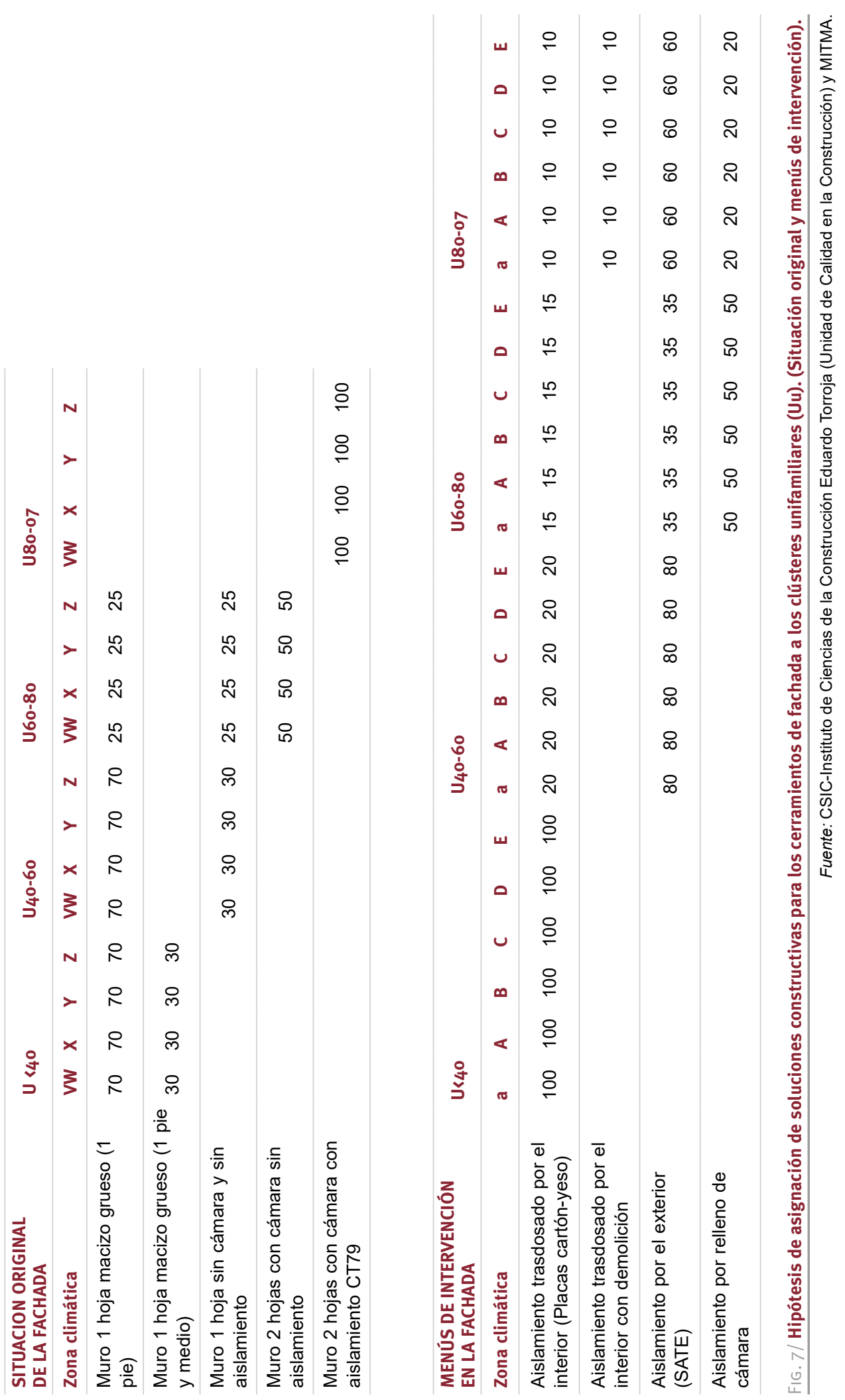
Para cada una de las soluciones constructivas de cada elemento de cerramiento, la Unidad de Calidad en la Construcción del CSIC-Instituto de Ciencias de la Construcción Eduardo Torroja ha calculado los correspondientes parámetros de transmitancia térmica $\left(\mathrm{W} / \mathrm{m}^{2} \mathrm{~K}\right)$, que, aplicados sobre la geometría correspondiente, permiten calcular la demanda energética de cada tipología edificatoria de referencia, según la zona climática en que se encuentre.

Con todos estos datos de partida, más las condiciones climáticas de cada zona, la metodología del cálculo de la demanda utiliza un método estático, aplicado mes a mes, y basado en el cálculo del balance energético, considerando los principales factores que inciden en el intercambio de energía con el exterior. Dada su complejidad, puede consultarse en la ERESEE 2020 y en el trabajo específico desarrollado para MITMA por ARCAS-ABELLA \& al., (2018).

Es importante recordar que esta demanda del conjunto del parque de viviendas español es solamente teórica (la que correspondería a cada caso, como consecuencia de su volumetría, condiciones constructivas, localización geográfica, etc.) y que se recurre a ella porque en España no existen estudios sobre consumo real de energía en hogares segmentados por tipologías como las que se utilizan en la ERESEE 2020. Por tanto, es necesario realizar un ajuste entre esta demanda teórica y los datos de consumo energético real en el sector residencial, procedentes de MITERD y disponibles a través del modelo TIMES-SINERGIA ${ }^{23}$, coherente a su vez con los datos de consumo de energía total agregada en España que publica anualmente MITERD-IDAE en los Balances de Energía Final y en la serie estadística de "Consumo para usos y energías del sector residencial” (2010-2018) ${ }^{24}$.

Nuevamente, la metodología de este ajuste entre la demanda y el consumo real excede las posibilidades de este artículo y para ello nos remitimos a la propia ERESEE 2020 y al trabajo específico realizado para MITMA por CUCHÍ, ARCAS-ABELLA \& PAGÉS-RAMÓN (2017).

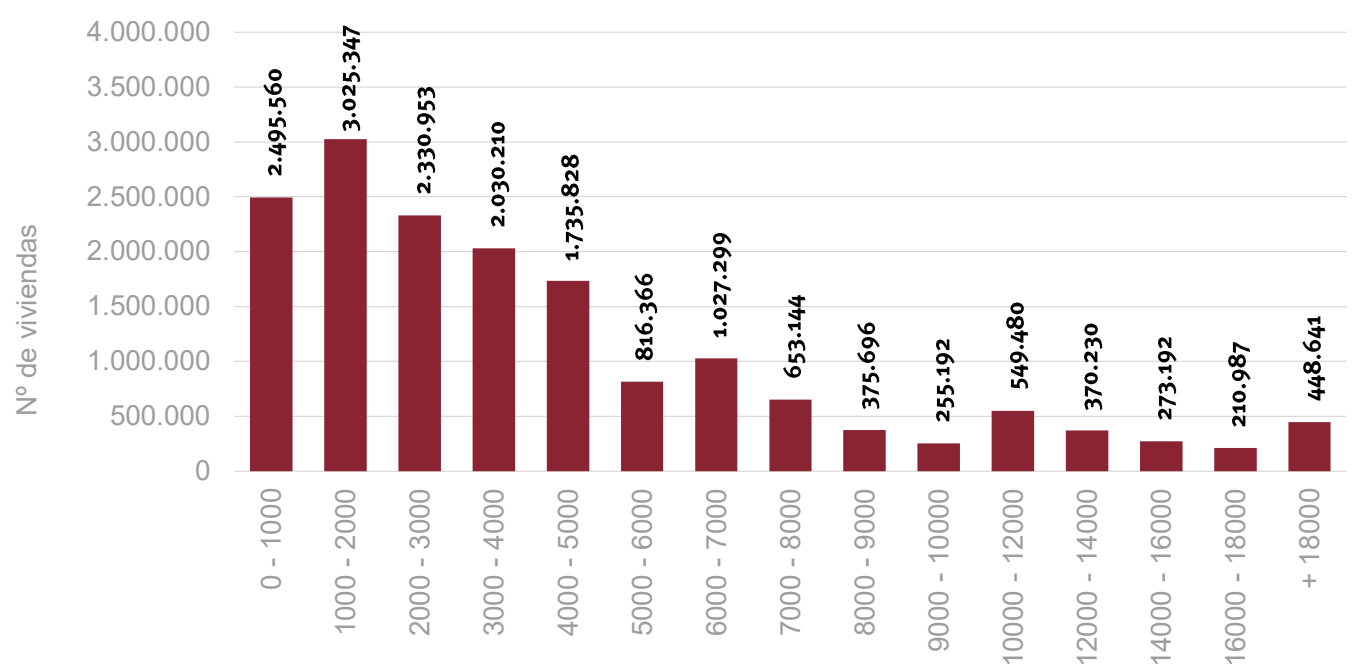

Consumo por vivienda -kWh/viv·año-

FIG. 8/ Desagregación del parque de viviendas español según rangos de consumo energético.

Fuente: Cíclica [Space, Community, Ecology] para MITMA.

${ }^{23}$ Para realizar el análisis del sistema energético y su prospectiva dentro del PNIEC 2030 se ha utilizado la herramienta TIMES (The Integrated MARKAL-EFOM System), creada originalmente por la Agencia Internacional de la Energía, en el marco del programa ETSAP (Energy Technology Systems Analysis Program) de desarrollo de análisis energéticos y medioambientales. En el caso español, el modelo TIMESSpain fue desarrollado por el Centro de Investigaciones Energéticas, Medioambientales y Tecnológicas (CIEMAT) tomando como año base el 2005. A partir de este modelo
TIMESSpain, desde la Dirección General de Política Energética y Minas (DGPEM), dependiente de la Secretaría de Estado de Energía del MITERD, se realizaron los trabajos necesarios para emplear TIMES como herramienta de prospectiva y análisis energético en la elaboración del PNIEC, generando un nuevo modelo, que es el que ha recibido el nombre de TIMES-SINERGIA (Sistema Integrado para el Estudio de la Energía).

${ }^{24}$ https://www.idae.es/estudios-informes-y-estadisticas 
Los resultados de todo este proceso permiten obtener el consumo desagregado para cada uno de los 37.800 casos diferentes analizados y agregarlo después - según convenga- por tipologías, clústeres, provincias, zonas climáticas, etc. En la FIG. 8 se ilustra la segregación del número de viviendas existentes según diferentes rangos de consumo, lo que confirma la importancia antes apuntada de focalizar las medidas estratégicas sobre estos hogares.

\section{Propuesta de enfoques de rehabilitación. Cálculo de los costes económicos y los ahorros de energía y emisiones}

La Directiva establece que las Estrategias nacionales deben determinar "enfoques económicamente rentables de las reformas apropiadas para el tipo de edificio y la zona climática". En el caso de la ERESEE 2020, para cada uno de los clústeres tipológicos y zonas climáticas se han desarrollado unos menús de rehabilitación óptimos, calculándose sus costes económicos y los ahorros de energía y emisiones que se obtendrían. Finalmente, como veremos más adelante, a partir de una serie de hipótesis sobre financiación -en las que se combinan subvenciones, préstamos, la capitalización de los ahorros energéticos, etc.- - se puede determinar el momento en que estas propuestas de rehabilitación serían viables para los propietarios.

Antes de definir los menús de rehabilitación, la ERESEE 2020 establece una serie de consideraciones de partida sobre el orden de intervención racional en los edificios, que sería el siguiente: 1), la racionalización del uso y la gestión del edificio; 2), la reducción de la demanda energética del edificio mediante la intervención en la envolvente (pérdidas por transmisión) y en la ventilación; 3), la mejora de la eficiencia energética de las instalaciones; y 4), el uso de energías renovables.

\subsection{La racionalización del uso y la gestión del edificio}

Estos dos elementos constituyen el primer factor a considerar en una intervención global en un edificio dirigida a tener un comportamiento eficiente en términos de energía y emisiones, puesto que los sistemas de climatización están definidos justamente para un uso y una gestión determinados. Por ejemplo, no tiene sentido invertir en una nueva caldera más eficiente y mejorar posteriormente el uso y la gestión, ocasionando una reducción sensible de la demanda para la cual esta nueva caldera resultará estar excesivamente sobredimensionada.

\subsection{Intervenciones sobre la envolvente. Optimización y propuesta de distribución territorial}

A grandes rasgos, la ERESEE 2020 plantea las siguientes propuestas sobre los elementos principales de la envolvente:

a) Cerramientos verticales - muros que separan el interior del exterior del edificio- donde se propone el aumento del aislamiento térmico hasta la máxima eficiencia posible (es decir, hasta el punto donde el aumento del aislamiento ya no produzca una mejora sensible en las pérdidas globales), bien por el interior (mediante relleno de cámara, o trasdosado interior), manteniendo el aspecto exterior de la fachada en los casos en que esto sea necesario (por ejemplo, en edificios históricos o acabados de fachada que deban mantenerse), bien colocando el aislamiento adosado por el exterior (sistema SATE o fachada ventilada), lo que permite mejorar notablemente el comportamiento de los puentes térmicos (cajas de persianas, cantos de forjados y soportes, jambas, etc.).

b) Carpinterías exteriores, donde se propone la mejora del aislamiento térmico y de la estanquidad a las infiltraciones, así como la protección solar de los huecos. Según los casos, se propone la sustitución de las ventanas existentes por carpinterías con vidrio doble y con rotura de puente térmico o la adición al hueco de la ventana existente de una nueva ventana con vidrio doble y rotura de puente térmico.

c) Cubiertas, donde se propone el aumento del aislamiento térmico hasta la máxima eficiencia posible. En cubiertas inclinadas de teja, cuando no exista cámara ventilada, se propone levantar las tejas para introducir aislamiento térmico y nueva capa de impermeabilización superior; cuando sí exista cámara ventilada y ésta sea accesible, se propone el trasdosado con aislamiento térmico por la parte inferior. En cubiertas planas, se propone la adición de una capa de aislante térmico y una protección superior transitable.

d) Soleras, donde se propone el aumento del aislamiento térmico hasta la máxima eficiencia posible bien mediante el adosado de un 
aislamiento térmico sobre el pavimento existente y nueva capa de pavimento ligero, con grosor total inferior a $7 \mathrm{cms}$; bien mediante la colocación de aislamiento térmico en la cámara, cuando existe forjado sanitario; o mediante la colocación de aislamiento por el inferior cuando se trata de forjado de planta baja al aire (soportales).

En cuanto a la reducción de la demanda mediante el control de la ventilación, se plantea la inclusión de la ventilación mecánica con recuperación de calor en la zona climática $\mathrm{E}$, siendo también aconsejable en la D. Sin embargo, en zonas con inviernos más suaves, la ventilación mecánica debería estudiarse de forma particularizada, evitando el concepto - propio de climas muy fríosde "vivienda-submarino" o estanca, que puede resultar chocante con la cultura de los usuarios y con las técnicas bioclimáticas tradicionales.

A partir de la definición constructiva del estado inicial y rehabilitado de la envolvente de cada caso y, junto con una serie de asunciones y datos de entrada (temperaturas de consigna, cargas internas por ocupación, iluminación y electrodomésticos, flujo de aire por ventilación, radiación solar) se realiza una doble simulación energética, para los escenario actual y futuro post-intervención. Estos cálculos permiten obtener los ahorros de energía y emisiones que se obtendrían tras la rehabilitación, así como el coste económico de las obras a realizar en la envolvente. En la tabla de la FIG. 9 se presenta el resumen de resultados por clústeres.

En la tabla de la FIG. 9 pueden constatarse las enormes diferencias existentes entre los costes de intervención y los ahorros obtenidos en cada clúster, cuyo cociente ilustra aún más gráficamente las diferentes rentabilidades que pueden obtenerse. Como se ha mencionado antes, estas diferencias se agudizan mucho más si además se tienen en cuenta las distintas zonas climáticas españolas. Es por ello que la ERESEE 2020 realiza una optimización de las intervenciones sobre las envolventes de las viviendas teniendo en cuenta este factor de rentabilidad económica. Para esta tarea, se comienza determinando el paquete de viviendas principales cuya envolvente se considera susceptible de ser rehabilitada, que resulta estar formado por 10.415 .037

\begin{tabular}{|c|c|c|c|c|c|c|c|c|}
\hline \multirow[b]{2}{*}{ Clúster } & \multirow[b]{2}{*}{$\begin{array}{c}\text { № } \\
\text { viviendas }\end{array}$} & \multicolumn{2}{|c|}{ Consumo inicial } & \multicolumn{3}{|c|}{ Ahorro energético } & \multicolumn{2}{|c|}{ Coste económico } \\
\hline & & $\begin{array}{c}\text { Total } \\
\text { GWh/año }\end{array}$ & $\begin{array}{c}\text { Vivienda } \\
\mathrm{kWh} / \text { viv•año }\end{array}$ & $\begin{array}{c}\text { Total } \\
\text { GWh/año }\end{array}$ & $\begin{array}{c}\text { Vivienda } \\
\mathrm{kWh} / \text { viv•año }\end{array}$ & $\begin{array}{c}\text { Total } \\
\%\end{array}$ & $\begin{array}{l}\text { Total } \\
\text { M€ }\end{array}$ & $\begin{array}{c}\text { Vivienda } \\
€ / \text { viv }\end{array}$ \\
\hline Uu $<1900$ & 215.462 & 3.145 & 14.597 & 2.484 & 11.528 & $79 \%$ & 3.058 & 14.192 \\
\hline Uu 01-40 & 332.726 & 4.368 & 13.129 & 3.461 & 10.403 & $79 \%$ & 4.381 & 13.167 \\
\hline Uu 41-60 & 461.697 & 4.944 & 10.709 & 3.853 & 8.345 & $78 \%$ & 7.194 & 15.582 \\
\hline Uu 61-80 & 941.372 & 10.779 & 11.450 & 8.053 & 8.555 & $75 \%$ & 14.945 & 15.875 \\
\hline Uu 81-07 & 2.207 .191 & 17.924 & 8.121 & 11.965 & 5.421 & $67 \%$ & 45.529 & 20.628 \\
\hline Cc $<1900$ & 53.643 & 349 & 6.508 & 253 & 4.710 & $72 \%$ & 557 & 10.386 \\
\hline Cc $01-40$ & 91.689 & 541 & 5.898 & 393 & 4.289 & $73 \%$ & 900 & 9.819 \\
\hline Cc 41-60 & 234.364 & 1.220 & 5.204 & 881 & 3.760 & $72 \%$ & 2.473 & 10.553 \\
\hline Cc $61-80$ & 559.767 & 2.068 & 3.694 & 1.352 & 2.416 & $65 \%$ & 4.817 & 8.606 \\
\hline Cc 81-07 & 1.018 .342 & 2.789 & 2.738 & 1.739 & 1.707 & $62 \%$ & 10.248 & 10.063 \\
\hline $\mathrm{Bb}<1900$ & 88.872 & 398 & 4.477 & 277 & 3.120 & $70 \%$ & 638 & 7.181 \\
\hline $\mathrm{Bb} 01-40$ & 192.968 & 846 & 4.382 & 590 & 3.059 & $70 \%$ & 1.359 & 7.043 \\
\hline $\mathrm{Bb} 41-60$ & 629.578 & 2.469 & 3.921 & 1.682 & 2.671 & $68 \%$ & 5.203 & 8.264 \\
\hline $\mathrm{Bb} 61-80$ & 3.310 .277 & 10.815 & 3.267 & 7.462 & 2.254 & $69 \%$ & 19.734 & 5.962 \\
\hline $\mathrm{Bb} 81-07$ & 2.942 .302 & 5.959 & 2.025 & 3.604 & 1.225 & $60 \%$ & 22.368 & 7.602 \\
\hline TOTAL & 13.280 .250 & 68.612 & 5.167 & 48.050 & 3.618 & $70 \%$ & 143.405 & 10.798 \\
\hline
\end{tabular}

FIG. 9/ Resumen de resultados por clúster de los menús de rehabilitación de las envolventes. 
unidade $^{25}$. A continuación, dentro de este paquete, se han ordenado todas las viviendas de mayor (viviendas unifamiliares, más grandes, y en zonas más frías) a menor rentabilidad económica (viviendas colectivas, más pequeñas, en zonas más cálidas), expresada como cociente entre la inversión necesaria para costear las obras según los menús correspondientes y los ahorros energéticos que se obtendrían.

En la FIG. 10 se representan en el eje de abscisas el número acumulado de viviendas rehabilitadas y en el eje de coordenadas, con dos escalas, el coste total acumulado de su rehabilitación (en GWh) y los ahorros que podrían obtenerse (en millones de $€$ ). Antes de su representación, se han ordenado todas las viviendas por eficacia, de manera que hacia la izquierda se representan las más rentables y hacia la derecha las menos. Como se observa, dada la muy diferente rentabilidad de las intervenciones, a partir de un determinado momento no resulta rentable rehabilitar más viviendas, pues siguen subiendo los costes totales (cuya función es más o menos una recta, es decir: son proporcionales al número de viviendas rehabilitadas), mientras que los ahorros acumulados prácticamente no crecen de forma significativa (al tener su función la forma de una curva que tiende a ser horizontal hacia la derecha).

A la vista de los gráficos de las FIGs. 10 y 11, se selecciona como "Paquete de Rehabilitación de Envolvente Prioritaria" el conjunto de los 7,1 millones de viviendas cuya rentabilidad está comprendida por encima del umbral de eficacia de $6 € / \mathrm{kWh}$, siendo el grupo de viviendas que presenta mayor eficacia energética y por lo tanto mayor potencial de mejora por cada $€$ invertido a partir de la rehabilitación de la envolvente.

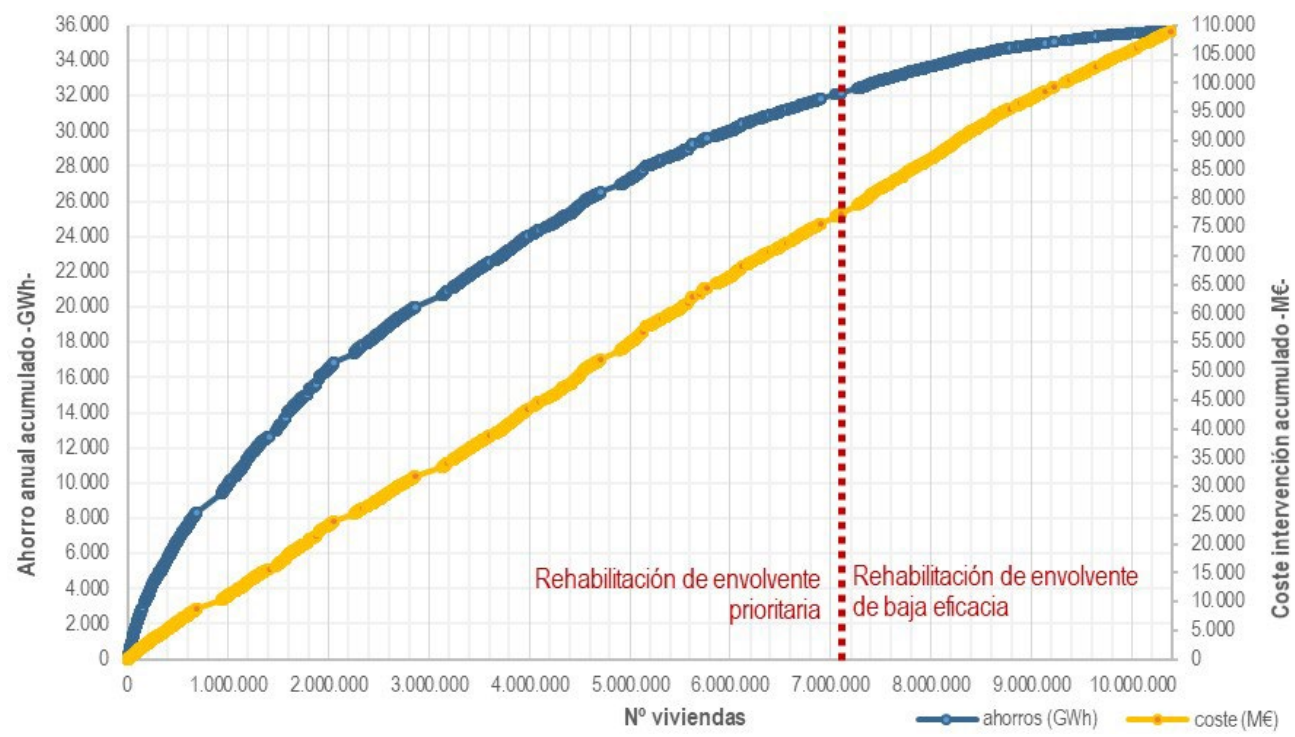

FIG. 10/ Distribución de viviendas según el potencial de rehabilitación energética.

Fuente: Cíclica [Space, Community, Ecology] para MITMA.

${ }^{25}$ Del total de 18.771 .653 viviendas principales existentes se descartan una serie de paquetes: como las que no tienen sistemas de calefacción y por tanto no consumen energía en este rubro (1.944.030 unidades), aquellas para las cuales no hay datos suficientes (6.178), o las que tienen sistemas de calefacción poco representativos (223.318), resultando un paquete (denominado "modelizable") de 16.598.127 viviendas. A este paquete se le restan los hogares en pobreza energética (2.572.361, que se analizan aparte) y las viviendas construidas entre 2008 y 2020 con los estándares ya vigentes del CTE (745.516 unidades), pues se supone que éstas no necesitarán rehabilitar energéticamente su envolvente. El paquete resultante (denominado de rehabilitación común") asciende a 13.280 .250 viviendas.

Sobre este subconjunto, se aplican 3 condicionantes previos simultáneos que limitan el número de viviendas a rehabilitar por caso, asumiendo la hipótesis que existen pocas probabilidades reales de rehabilitar el $100 \%$ de viviendas de cada caso. Estos condicionantes, previos al análisis de eficacia, establecen la cantidad de viviendas a rehabilitar por caso según los siguientes criterios: un máximo del $80 \%$ en cada caso: por período de construcción, un $80 \%$ antes de 1940 y $100 \%$ después de 1940; y, según tamaño de municipio, un $80 \%$ en zonas rurales y $100 \%$ en urbanas. La aplicación conjunta de estos 3 condicionantes descarta otras 2.865.213 viviendas como de rehabilitación "Poco Probable", y da como resultado el paquete de viviendas "Rehabilitación Potencial de Envolvente" con un total de 10.415.037 viviendas, que es el que se ordena en el gráfico. 


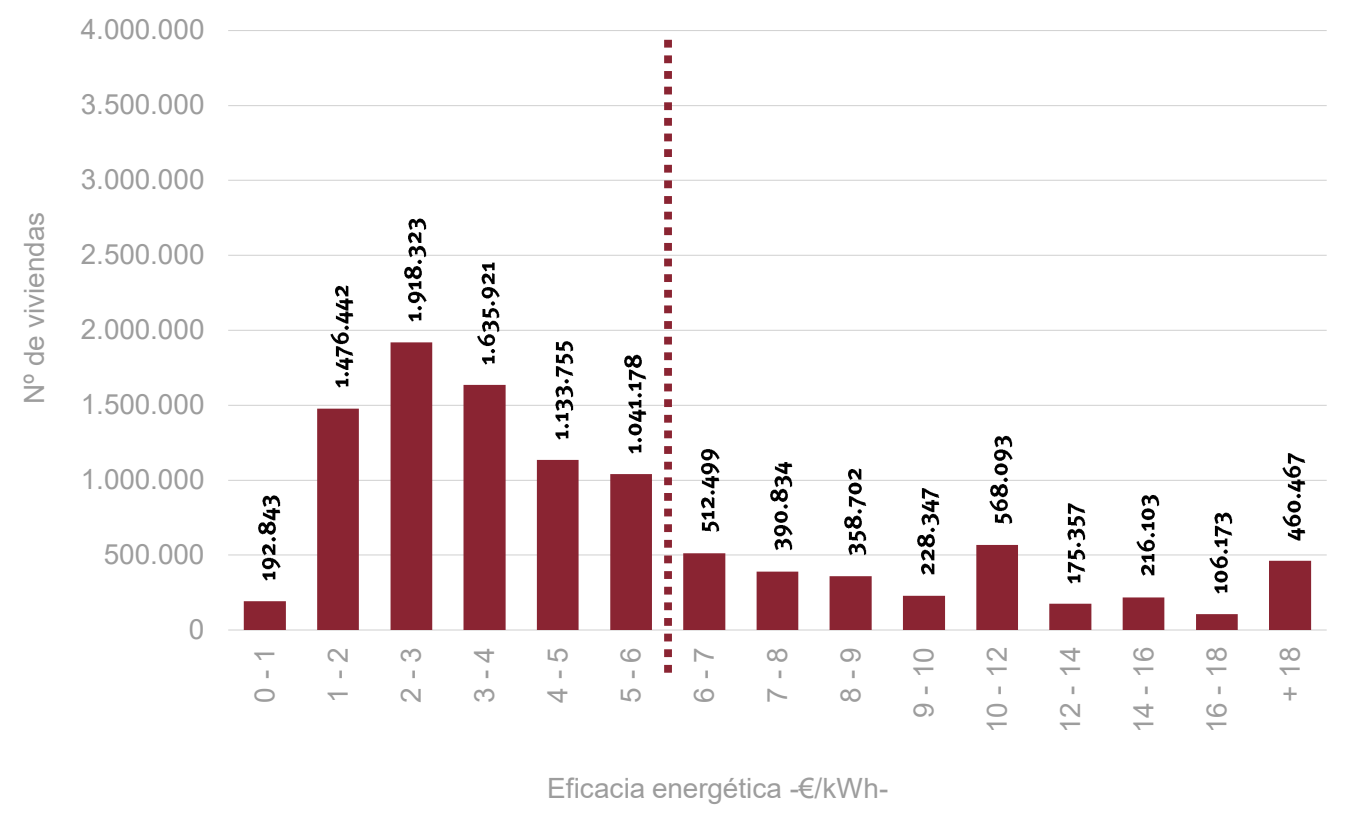

Nota: A la izquierda de la línea de puntos están las viviendas que se rehabilitan.

FIG. 11/ Distribución de viviendas según el indicador de eficacia energética $-€ / k W h-$

Fuente: Cíclica [Space, Community, Ecology] para MITMA.

De esta forma, se cuenta con un paquete de 7,1 millones de viviendas de "Rehabilitación de Envolvente Prioritaria", sobre el cual se van a plantear los diferentes escenarios de intervención sobre la envolvente. Por supuesto se conoce la distribución tipológica y territorial de estas viviendas y es posible su secuenciación temporal. Por ejemplo, para el paquete de 1,2 millones de viviendas a rehabilitar antes del año 2030, la propuesta de distribución por clústeres y Comunidades Autónomas sería la que se ve en la tabla de la FIG. 12.

\subsection{Otros menús para la envolvente: actuaciones pasivas y bioclimáticas para condiciones de verano y menús parciales}

Además de los menús de intervención completa sobre la envolvente, se plantean otras actuaciones pasivas y bioclimáticas para las condiciones de verano, como medidas de mejora del aislamiento, en especial en cubiertas, y de sombreamiento de fachadas y protección de huecos (toldos, parasoles, voladizos, etc.).

También se analizan distintas posibilidades de actuaciones parciales, siempre con la precaución de que no entren en competencia o en contradicción con las medidas de rehabilitación profunda de la envolvente propuestas, retrasándolas o incluso desincentivándolas. Se destacan muy especialmente las sinergias que se pueden dar entre obras de conservación en fachadas y cubiertas y la mejora de la eficiencia energética. En este sentido, la Inspección Técnica de Edificios (ITE), el Informe de Evaluación de Edificios (IEE) o el Pasaporte del Edificio, son herramientas que pueden ser muy importantes en la creación de estas sinergias, tan sólo suponiendo que entre el 5 y el $10 \%$ de las viviendas teóricamente obligadas a pasar el IEE deban realizar obras de conservación obligatorias en las fachadas, esto podría suponer activar estas sinergias en una horquilla de entre más de 337.000 y 674.000 viviendas colectivas solo en la próxima década ${ }^{26}$.

\footnotetext{
${ }^{26}$ La cantidad es muy notable, teniendo en cuenta el objeti-
} vo previsto de intervenir en 1,2 millones en este período. 


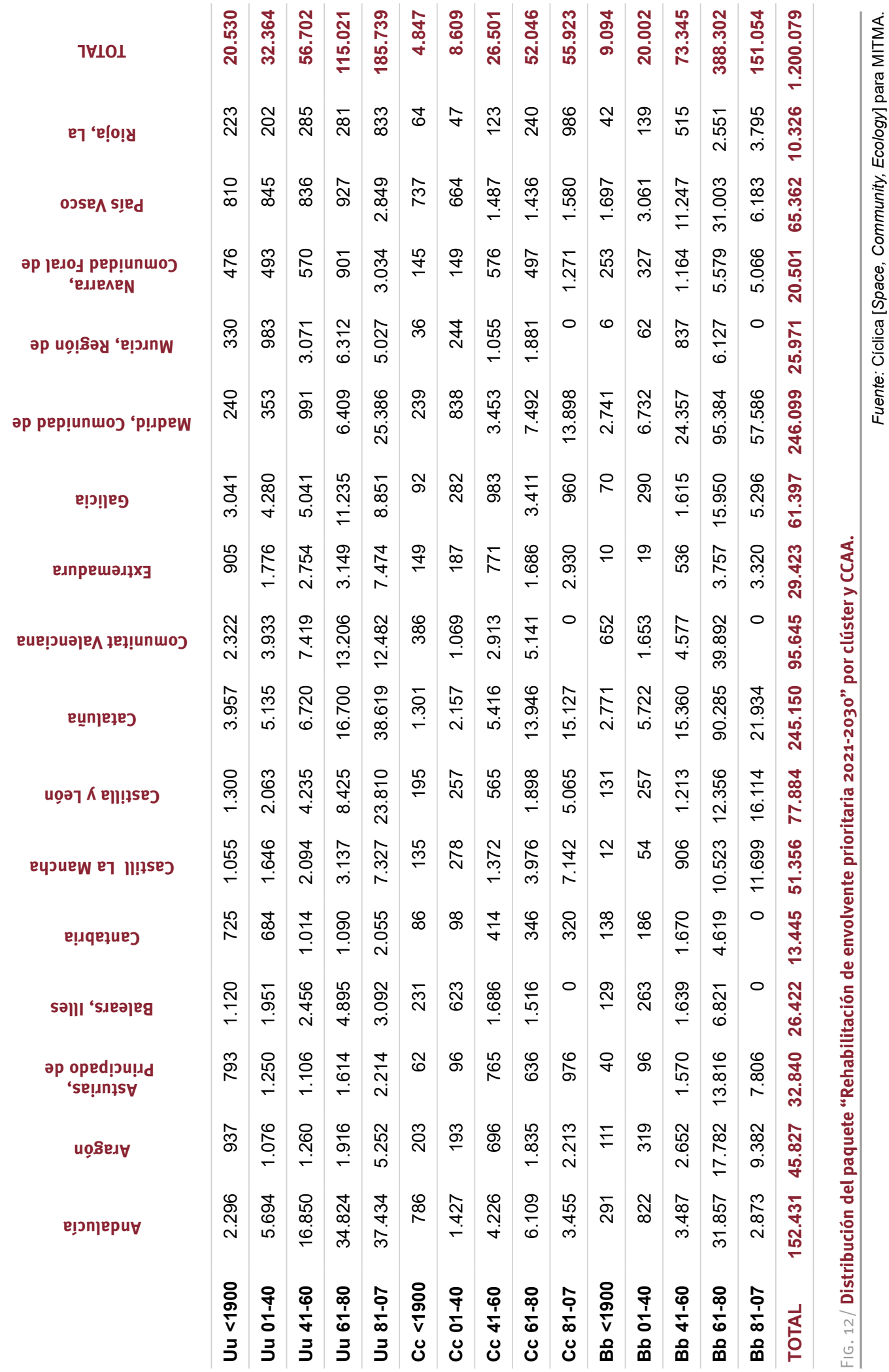


6.4. La mejora de la eficiencia energética de las instalaciones e implantación de energías renovables: Matrices de cambios de instalaciones

Antes de abordar las propuestas de cambios de instalaciones, la ERESEE 2020 incluye toda una serie de principios y recomendaciones de orden general a tener en cuenta para su correcto planteamiento y secuenciación, en particular en relación con las instalaciones de biomasa, la energía solar y la bomba de calor ${ }^{27}$.

Para la modelización de los cambios de instalaciones de calefacción MITMA ha elaborado una tabla matriz que permite calcular los equipos, consumos e inversiones a 2030, introduciendo los datos de partida de 2020 de las viviendas segmentadas por paquetes y en coherencia con la modelización de las instalaciones realizada por MITMA a partir de TIMES-SINERGIA para ELP 2050. La tabla funciona a partir de:

- Unos coeficientes que determinan el número de equipos que deben renovarse de cada tecnología. El coeficiente de hogares que, sin cambiar de tecnología, renuevan los equipos se obtiene a partir de la vida útil de los equipos según MITERD y el CSICInstituto de Ciencias de la Construcción Eduardo Torroja (Unidad de Calidad en la Construcción). El coeficiente de hogares que cambian de tecnología y combustible es una hipótesis del modelo de MITMA a partir de la senda de número de equipos y combustibles de las tablas de TIMESSINERGIA, para cumplir los objetivos marcados por el PNIEC. La asignación se realiza para vivienda unifamiliar, plurifamiliar con sistemas individuales y plurifamiliar con sistemas colectivos (agrupándose estas en la matriz final en proporción a su distribución a nivel nacional, pues no se dispone de datos desagregados territorialmente de equipos colectivos e individuales). Para el diseño de estos coeficientes se han tenido en cuenta las propuestas del trabajo ATECYR (2019) para MITMA. Se han hecho 5 hipótesis de estos coeficientes, tomándose finalmente la que más se ajusta a la senda de cambios de combustibles propuesta por PNIEC.

- Unos coeficientes de relación entre los consumos iniciales a 2020 y los finales a 2030 , elaborados por MITMA y el CSIC-Instituto de Ciencias de la Construcción Eduardo Torroja (Unidad de Calidad en la Construcción) a partir de los rendimientos de los equipos y tecnologías de los equipos existentes y renovados (con las correspondientes hipótesis de fechas) usados en el modelo TIMESSINERGIA.

- Unos precios de los equipos nuevos o renovados, desarrollados por el CSIC-Instituto de Ciencias de la Construcción Eduardo Torroja (Unidad de Calidad en la Construcción).

Como salida, las matrices ofrecen:

- Número de equipos de calefacción renovados sin cambio de combustible, con cambio de combustible y que permanecen sin renovar.

- Energía consumida y ahorros.

- Costes de las renovaciones sin cambio y con cambio de combustible.

\subsubsection{Matrices de criterios de cambios en las instalaciones de calefacción para el Escenario Objetivo}

A continuación, se recogen las matrices de criterios de cambios en las instalaciones, desarrolladas a partir de las propuestas del trabajo citado de ATECYR y con el objetivo final de ajustarse a los consumos por combustible en 2030 marcados por PNIEC y el modelo TIMES-SINERGIA.

El diseño se hace distinguiendo instalaciones en viviendas plurifamiliares con sistemas colectivos y con sistemas individuales, por un lado, y viviendas unifamiliares, por otro.

La lectura de la matriz (FIG. 13) es la siguiente:

\footnotetext{
${ }^{27}$ Sobre esta última, y dada la tendencia a la electrificación a largo plazo, se analizan con detalle las limitaciones existentes para su implantación en la actualidad en determinadas condiciones climáticas, así como las posibilidades de su implantación en viviendas que actualmente cuentan con sistemas de climatización con caldera, tuberías de agua y radiadores. Dado que un cambio completo de sistema sería muy costoso y complejo, se apunta la posibilidad de que una
} 


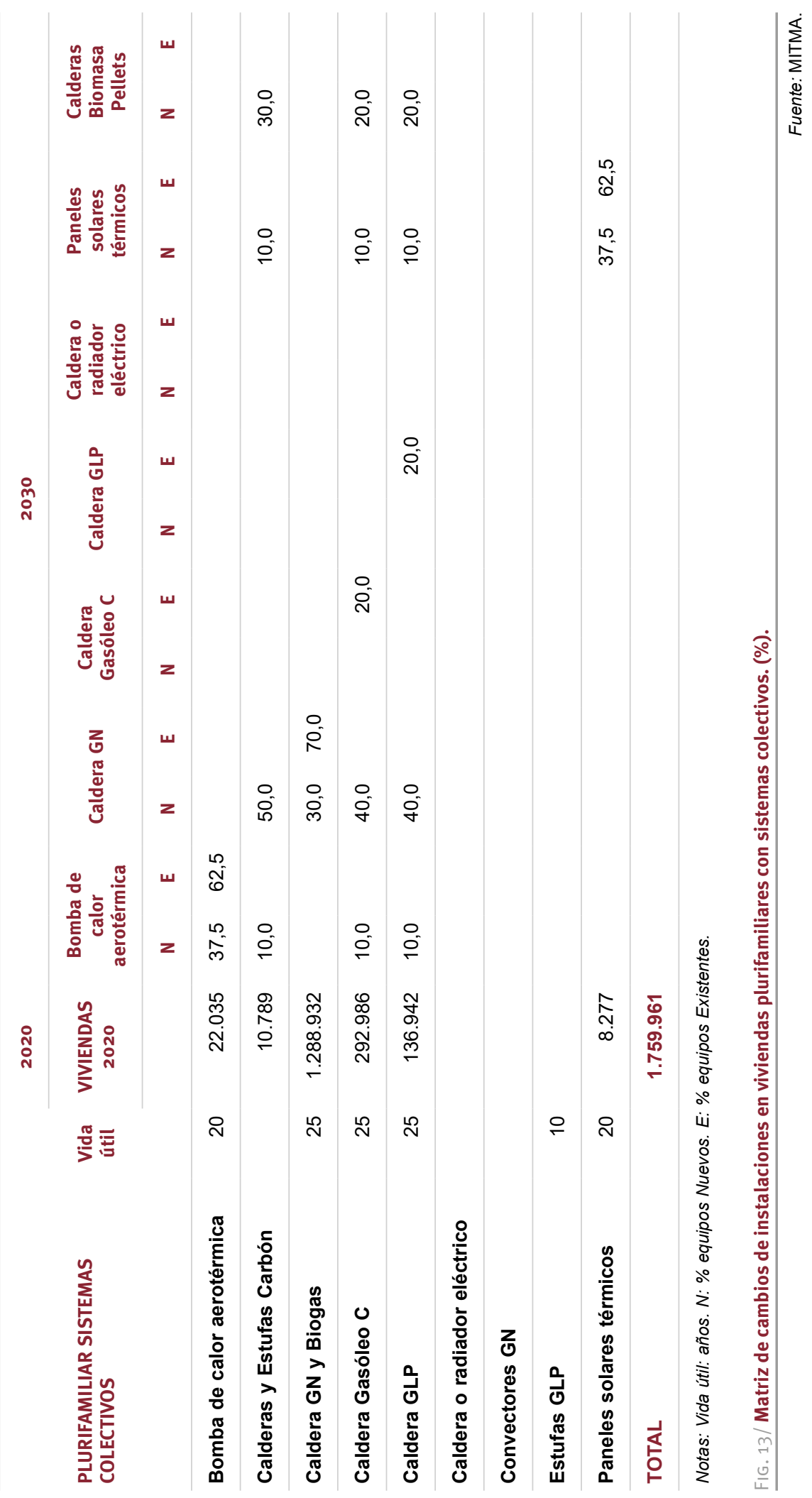


- Bombas de calor aerotérmicas. En 2030 se supone que se mantienen los equipos existentes en 2020, renovándose los que correspondan en función del agotamiento de su vida útil estimada ${ }^{28}$ (un $37,5 \%$ ).

- Calderas centrales de carbón. El objetivo es eliminarlas completamente en 2030. Se hace la hipótesis de su sustitución en un $50 \%$ por calderas centrales de Gas Natural (en zonas urbanas), en un $30 \%$ por calderas centrales de Biomasa (en zonas rurales, transformando la carbonera en almacén para la biomasa), y suponiendo que el $20 \%$ restante (correspondiente a edificios pequeños con pocas viviendas) podrá repartirse a partes iguales entre pequeñas Bombas de Calor centralizadas $(10 \%)$ y sistemas colectivos con Paneles Solares Térmicos (10\%).

- Calderas centrales de Gas Natural. Se supone que se mantienen las existentes, renovándose las que corresponda por agotamiento de su vida útil teórica - estimada en 25 años-y prórroga de ésta en un $25 \%$ suplementario (lo que supone finalmente una tasa de renovación del $26,8 \%$ ).

- Calderas de Gasóleo y Calderas de GLP. En ambos casos, el objetivo es la sustitución del mayor número de equipos posibles a 2030, estimándose que en esa fecha sólo quedará el $20 \%$ del número de equipos actuales. Se supone que un $40 \%$ de los actuales se cambiará a calderas colectivas de Gas Natural (en zonas urbanas), y que otro $20 \%$ (zonas rurales) podrá pasar a Biomasa, correspondiendo el $20 \%$ restante a hogares en pequeños edificios de vivienda colectiva donde puede resultar viable cambiar a Bomba de Calor centralizada o a Paneles Solares Térmicos colectivos.

- Los equipos restantes existentes en 2020, que son los Paneles Solares Térmicos, se mantienen a 2030 , renovándose los que correspondan (se supone un $37,5 \%$ ).

En vivienda plurifamiliar con sistemas individuales se realizan las siguientes hipótesis a 2030 (FIG. 14):

- Bombas de calor aerotérmicas. Se mantienen los equipos existentes, renovándose el $75 \%$ de los que corresponden en función del agotamiento y prórroga de su vida útil estimada (lo que supone una tasa de renovación del $37,5 \%$ ).

\footnotetext{
${ }^{28}$ Para todos los equipos considerados, y como hipótesis conservadora, se supone que los hogares (por diversas circunstancias, sobre todo, por su situación económica) "estiran"
}

- Calderas y estufas de carbón. El objetivo es eliminarlas completamente en 2030. Se hace la hipótesis de su sustitución en un $40 \%$ por calderas individuales de Gas Natural (en zonas urbanas), en un 30\% por calderas de Biomasa (en zonas rurales, transformando la carbonera en almacén para la biomasa), y suponiendo que el $30 \%$ restante corresponde a Estufas (por tanto, sin circuito ni radiadores) y que éstas se sustituyen por Bombas de Calor $(20 \%)$ o por Radiadores Eléctricos (10\%).

- Calderas individuales de Gas Natural. Se supone que se mantienen las existentes, renovándose el $75 \%$ de las que corresponda por agotamiento de su vida útil, estimada en 15 años (lo cual supone una tasa final de renovación del $50 \%$ ).

- Calderas de Gasóleo y Calderas de GLP. En ambos casos, el objetivo es la sustitución del mayor número de equipos posibles a 2030, estimándose realista que en esa fecha sólo quede el $20 \%$ del número de equipos actuales, procurando mayoritariamente mantener el resto de la instalación existente (circuito y radiadores). Se supone que un $40 \%$ de los actuales se cambiará a calderas individuales de Gas Natural (en zonas urbanas), y que otro $25 \%$ (zonas rurales) podrá pasar a calderas individuales de Biomasa. En el 15\% de los casos restantes, se supone que se producirá un cambio más profundo, desmantelándose la instalación existente para pasar a Bomba de Calor (10\%, especialmente en zonas con alta necesidad de refrigeración) o a Radiadores Eléctricos (sólo un 5\%).

- Equipos Eléctricos, que pueden ser: Radiadores Eléctricos, Calderas Eléctricas (que calientan agua que circula por un circuito de distribución que sirve a radiadores) y, en menor medida, Hilo Radiante. Se supone que en 2030 se mantienen aquellas (un $62,5 \%$ ) que no han agotado su vida útil teórica - estimada en 20 años - o la prorrogan en la práctica, y que el resto, a partes iguales, o bien se renueva o bien pasa a Bomba de Calor.

- Finalmente, para los equipos restantes (Convectores de Gas Natural y Estufas de GLP), el objetivo es su completa sustitución en 2030 por otros más eficientes: un $70 \%$ por Bomba de Calor y un 30\% por algún Sistema Eléctrico de los mencionados más arriba.

al máximo la vida útil de los equipos, con el resultado final de que sólo se renuevan el $75 \%$ de los equipos que teóricamente correspondería por agotamiento de su vida útil. 


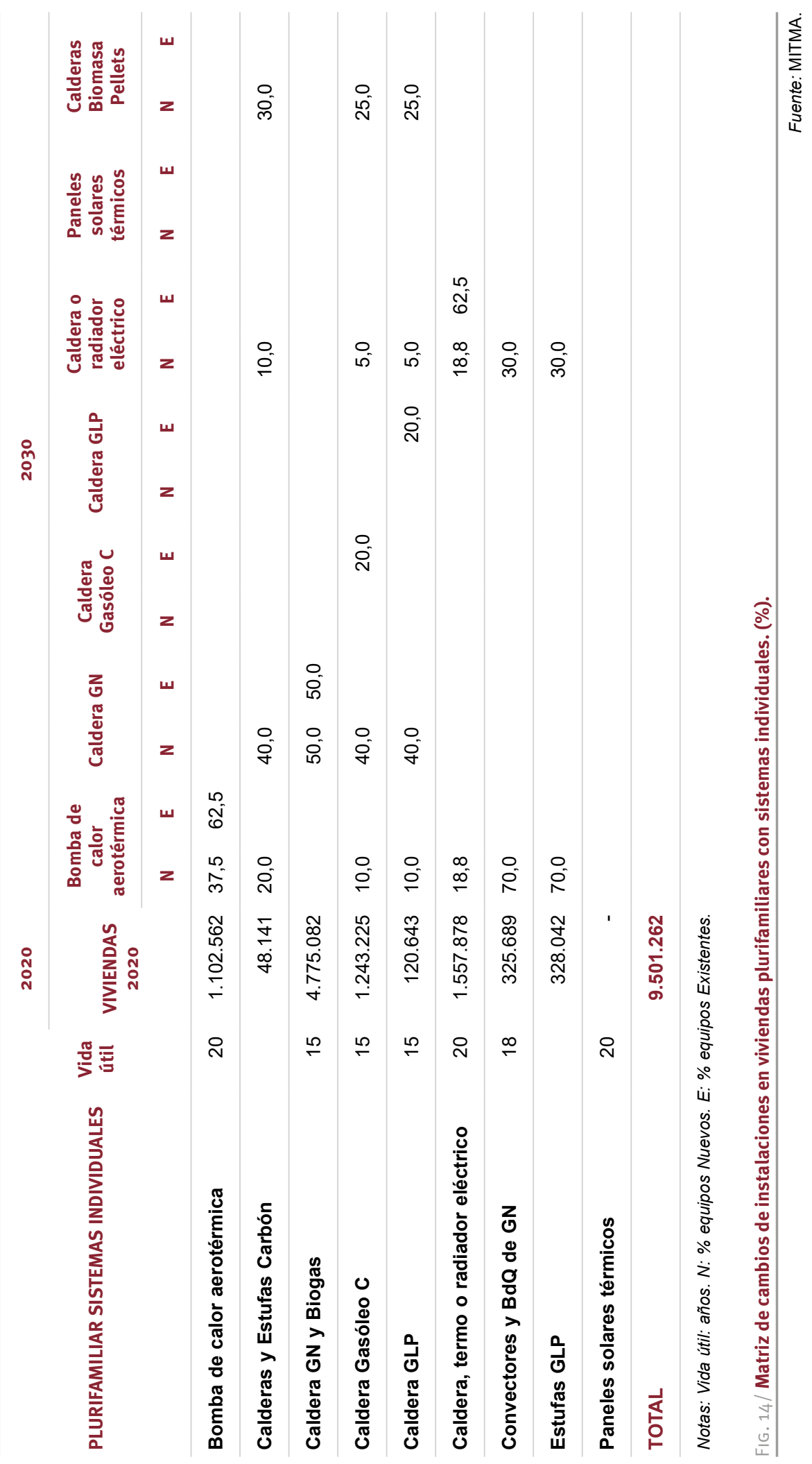


Con todo ello, y aplicando las hipótesis de distribución anteriores al número de equipos centrales e individuales existentes a nivel nacional, se obtiene el reparto proporcional para el conjunto de viviendas plurifamiliares que se ve en la tabla de la FIG. 15.

En el caso de las viviendas unifamiliares, las hipótesis de cambios en las instalaciones son las siguientes, que se recogen en el cuadro de la FIG. 16.

- Bomba de Calor. Se mantienen los equipos existentes en 2020 , renovándose entre 2020 y 2030 el $75 \%$ de los que corresponda por agotamiento de su vida útil (lo que supone un $37,5 \%)$.

- Estufas y calderas de Carbón. El objetivo es eliminarlas en 2030, suponiéndose que las viviendas que tienen un sistema de calefacción propiamente de dicho (caldera, circuito de distribución de agua y radiadores) cambian a Biomasa $(20 \%)$, Paneles Solares Térmicos (20\%) o Gas Natural $(10 \%)$, mientras que las viviendas donde sólo hay Estufas de Carbón pasan a Bomba de Calor $(10 \%)$ o a Casettes de Chimenea con Biomasa (40\%).

- Calderas de Gas Natural. Se supone que se mantienen un $50 \%$ de los equipos existentes en 2020: lo que incluye —además de los que siguen dentro de su vida útil teórica (estimada en 15 años) - un $25 \%$ de los que deberían renovarse, pero que se ha supuesto que prolongan en la práctica esta vida útil teórica. Del $50 \%$ restante, un $30 \%$ se renueva manteniendo el Gas Natural, pero se supone que un $20 \%$ comienza ya la transición hacia otras fuentes de energía no fósil, ya que —en el escenario final previsto en 2050 - se supone que la energía de procedencia fósil $-\mathrm{y}$, en particular, el Gas Natural- deberá haber desaparecido completamente en las viviendas unifamiliares. Este $20 \%$ se supone que cambia a Calderas de Biomasa (10\%) o a Bomba de Calor (10\%).

- Calderas de Gasóleo y GLP. Como ocurriera en vivienda plurifamiliar, en ambos casos, el objetivo es la sustitución del mayor número de equipos posibles a 2030 , estimándose como realista que en esa fecha sólo quede el $20 \%$ del número de equipos actuales, procurándose mayoritariamente mantener el resto de la instalación existente (circuito y radiadores). Se supone que un $20 \%$ de los equipos actuales se cambiará a calderas de Gas Natural (en zonas urbanas), y que otro $20 \%$ (zonas rurales) pasará a calderas individuales de Biomasa. En el $40 \%$ de los casos restantes, se supone que un $20 \%$ se podrá cambiar a Paneles Solares Térmicos (20\%), un $10 \%$ a Bomba de Calor (especialmente en zonas con alta necesidad de refrigeración) y otro $10 \%$ a Sistemas Eléctricos.

- Equipos Eléctricos en viviendas unifamiliares, que pueden ser o bien Radiadores Eléctricos, Calderas Eléctricas (que calientan agua que circula por un circuito de distribución, dando servicio a los radiadores) y, en menor medida, Hilo Radiante. Se supone que en 2030 se mantendrán aquellos equipos que estén dentro de su vida útil teórica (20 años) o el 25\% que la alarguen aún más allá (resultando en total el 62,5\%) y que el resto pasará o bien a Bomba de Calor (estimado en un $27,5 \%$, fundamentalmente correspondiente al caso de Radiadores Eléctricos que se desmantelen) o a Paneles Solares Térmicos (10\%).

- Convectores de Gas Natural y Estufas de GLP. Se supone que ambos sistemas desaparecerán completamente en 2030, estimándose que mayoritariamente serán sustituidas por equipos individuales que no precisan instalar ex novo un sistema de calefacción completo, como Bombas de Calor $(30 \%)$, Casettes de Biomasa (40\%) o algún Sistema Eléctrico (20\%), y, en menor medida, a Paneles Solares Térmicos (10\%).

- Como se ha comentado, la Biomasa en viviendas unifamiliares tiene una importante contribución al consumo en el sector residencial en 2020 y por tanto su evolución a 2030 es determinante. Se ha supuesto que las viviendas existentes en 2020 con Calderas de Biomasa con Pellets se mantienen en 2030 , renovándose el $50 \%$ de las mismas. Por su parte, las que disponen de Chimeneas o Estufas de Leña —que son las viviendas con mayor consumo unitario relativo, y además representan un porcentaje muy elevado del consumo total- se supone que se quedarán como están en un $30 \%$, que otro $50 \%$ mantendrá la Biomasa aunque mejorarán de forma sencilla y barata los rendimientos mediante la simple instalación de Casettes (en un $40 \%$ de los hogares) o bien realizarán una instalación completa con caldera, circuito y radiadores en un porcentaje bastante menor de los casos (10\%). Se estima que el $20 \%$ restante, sobre todo en zonas con demanda de refrigeración, pasará a Bomba de Calor.

Por último, en las pocas viviendas existentes con geotermia (estimadas en menos de 25.000) se supone que no hay cambios significativos entre 2020 y 2030 (FIGS. 17 y 18). 


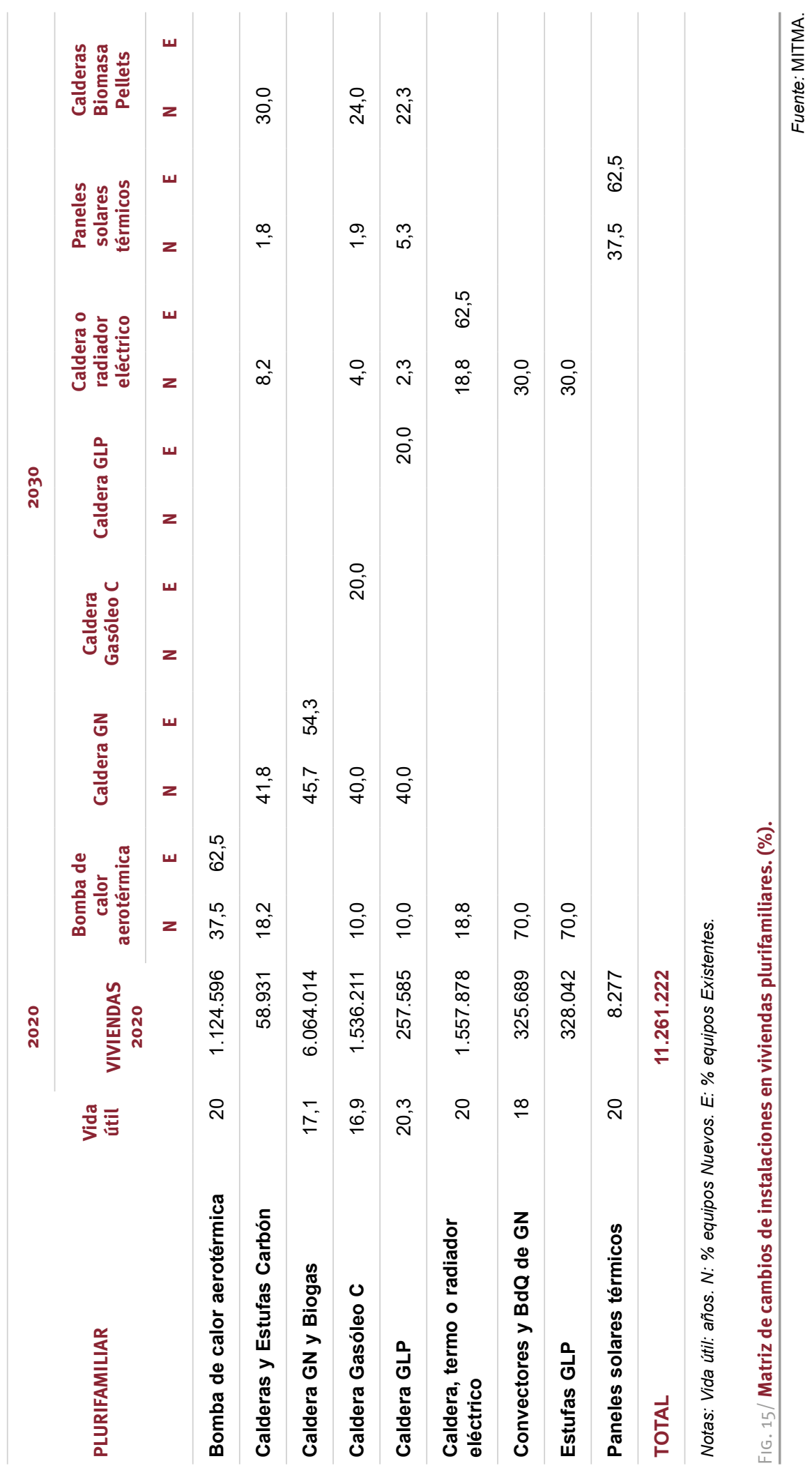




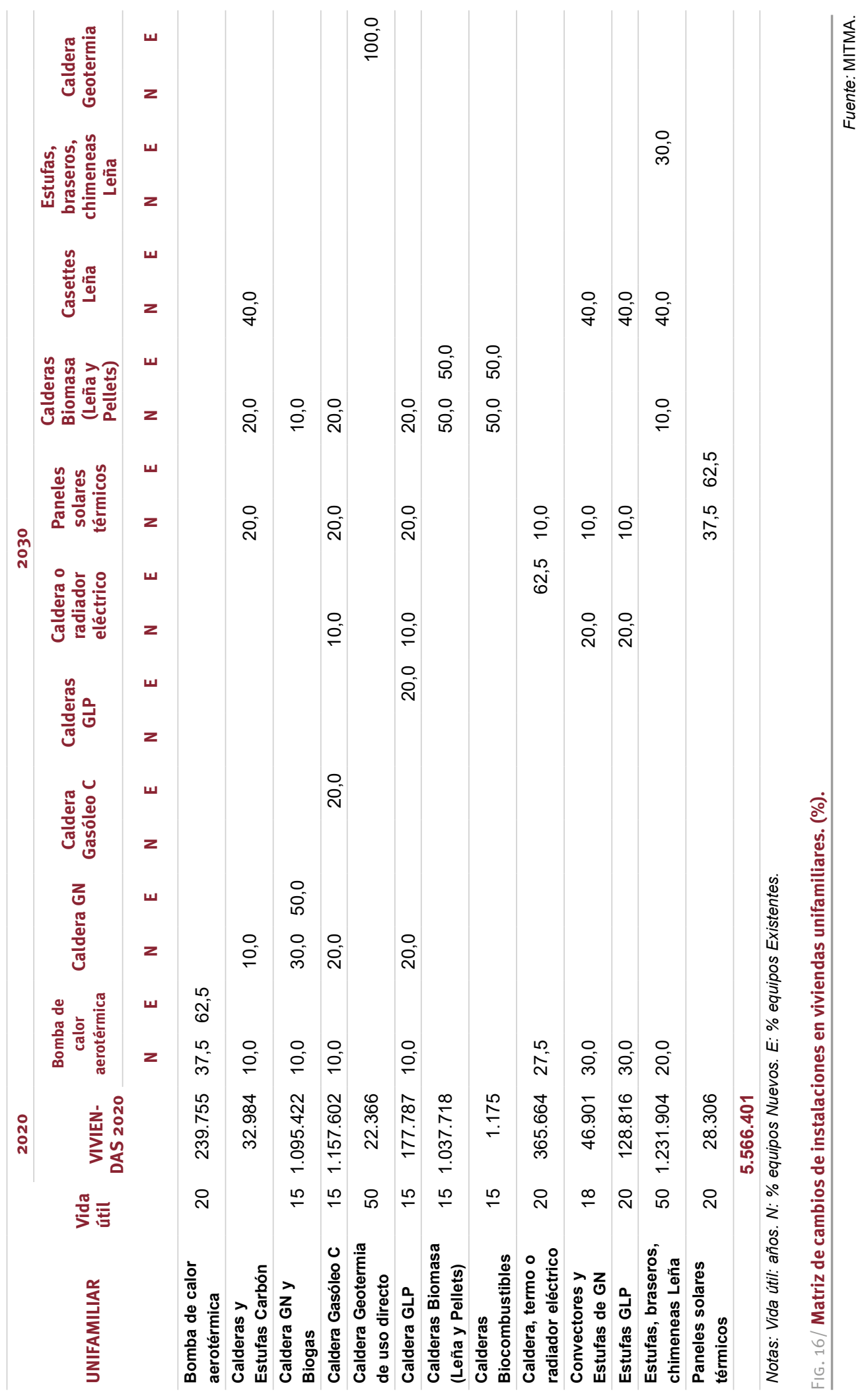




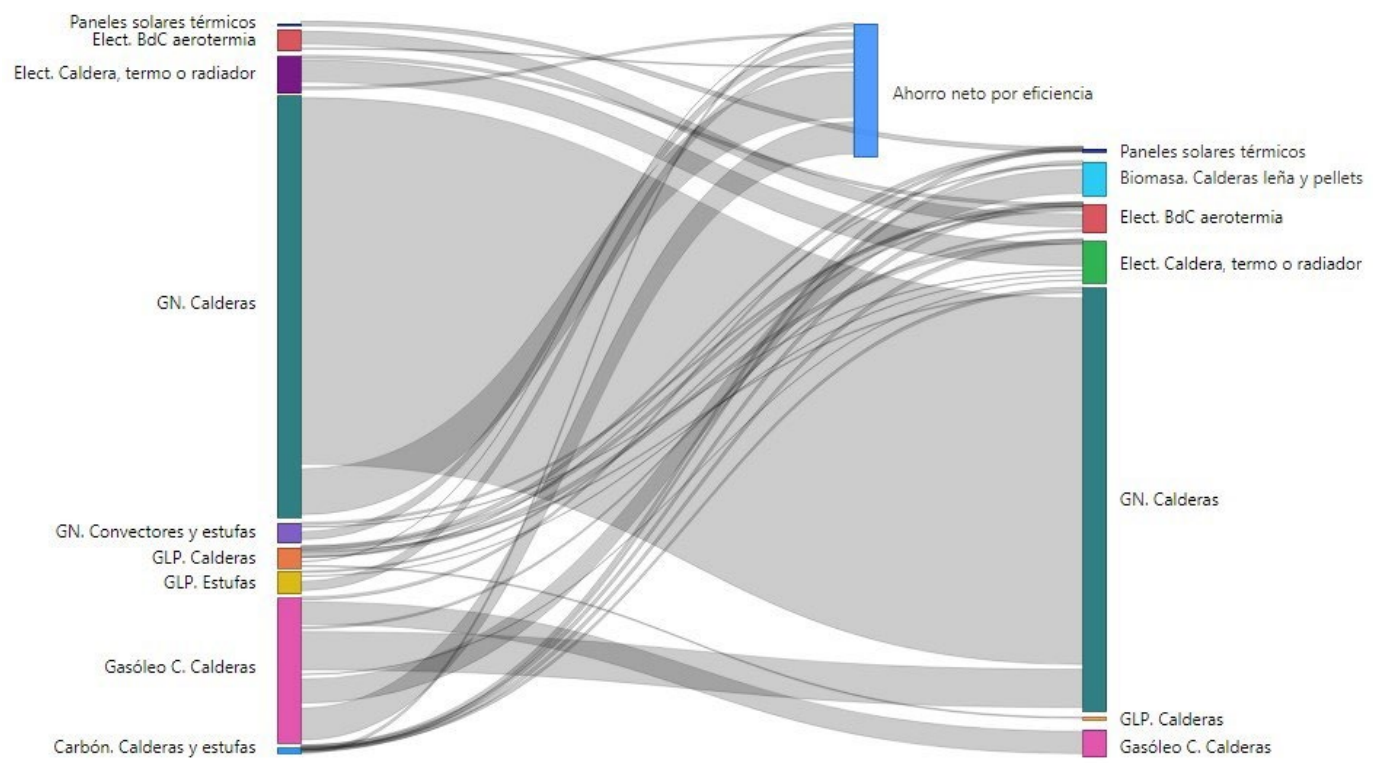

FIG. 17/ Diagrama de cambios en el consumo para Calefacción en viviendas plurifamiliares según combustibles (izquierda 2020, derecha 2030). Escenario C (Base).

Fuente: MITMA.

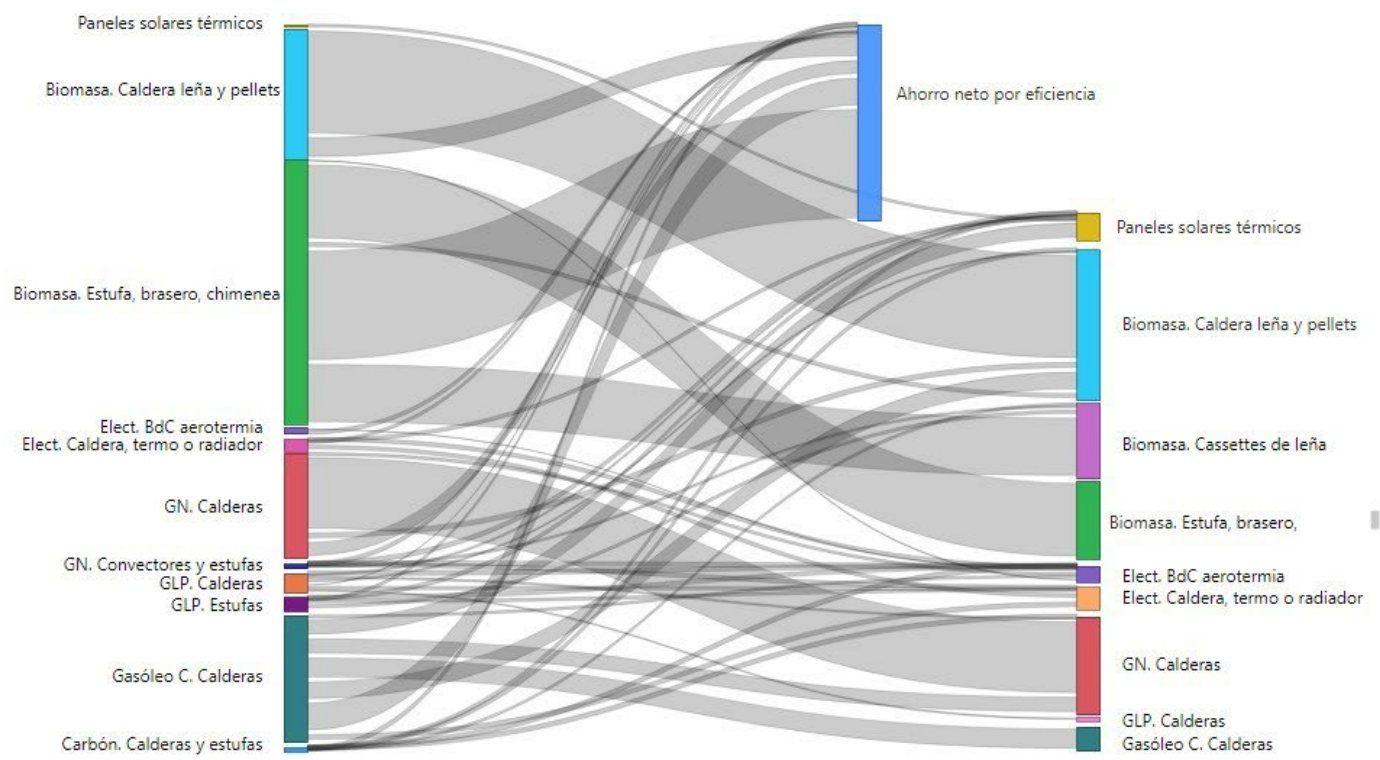

FIG. 18/ Diagrama de cambios en el consumo para Calefacción en viviendas unifamiliares según combustibles (izquierda 2020, derecha 2030). Escenario C (Base). 


\subsubsection{Matrices de ACS para el Escenario Objetivo}

La hipótesis del Escenario Objetivo para ACS se ha construido en base a dos criterios: el primero, la aplicación de los cambios de combustible necesarios para cumplir los objetivos generales del PNIEC en 2030, y, el segundo, la renovación de todos los equipos a los que se les agota teóricamente la vida útil estimada dentro de la década 2020-2030, sin considerar - como en la hipótesis tendencial- que un determinado porcentaje de los hogares vaya a prorrogar su uso.

Los cambios de combustible previstos implican la completa desaparición del Carbón en 2030, así como reducciones muy significativas de los equipos de ACS que usan Gasoil, GLP y —dentro de la Biomasa- Leña.

La renovación de equipos y su sustitución por otros más eficientes -pero con el mismo combustible- es particularmente intensa (alcanzando aproximadamente a $2 / 3$ de los existentes) en los Calentadores y Calderas Mixtas de Gas Natural y en los Termos y Calderas Mixtas Eléctricas.

Por su parte, como ocurre con los equipos de las viviendas de nueva construcción, se supone que los equipos que sustituyen a otros con cambio de combustible se dirigen mayoritariamente hacia el Gas Natural, la Bomba de Calor con ACS y los Paneles Solares.

Además de los equipos de las viviendas de nuevas de construcción (cuya distribución se supone idéntica a la de la hipótesis tendencial), en total, según este Escenario Objetivo habría 9.734.480 equipos que se renovarían sin cambiar de combustible, 5.835.937 que permanecerían sin renovarse y 3.201 .236 equipos que se renovarían cambiando también de combustible.

Los resultados desglosados por combustible se recogen en la tabla de la FIG. 19.

\section{Diseño y selección de escenarios. Cuantificación de las inversiones necesarias}

Teniendo en cuenta las hipótesis y escenarios parciales sobre la envolvente y las instalaciones de calefacción y ACS descritos anteriormente, en la ERESEE 2020 se han calculado y analizado los siguientes 6 escenarios para la década 2020-2030:

Escenario A: "Escenario Tendencial", considerando que no hay inversiones en rehabilitación de la envolvente y que las instalaciones solamente se renuevan cuando concluye su vida útil.

Escenario B: "Escenario Sólo Instalaciones", considerando que no hay inversiones en rehabilitación de la envolvente y pero que, en las instalaciones, además de la simple renovación por agotamiento de su vida útil, se producen los cambios de equipos necesarios para tratar de conseguir los objetivos del PNIEC.

Escenario C: "Envolvente+Instalaciones (Base)". En este escenario se combina la intervención en las instalaciones de ACS y calefacción con la rehabilitación de la envolvente de 1.200.079 viviendas, siguiendo el objetivo numérico ya adelantado en su momento por el PNIEC.

Escenario D: "Envolvente+Instalaciones con optimización de la senda de la envolvente". En este escenario, con el mismo número de viviendas totales rehabilitadas, se adelanta el ritmo de intervenciones en la envolvente marcado por el PNIEC, acelerando especialmente el despegue de la rehabilitación en la primera parte de la década 2020-2030. Este escenario puede resultar especialmente adecuado para impulsar el sector de la edificación como medida de reactivación económica tras la pandemia del coronavirus.

Escenario E: "Envolvente+Instalaciones con optimización de las viviendas a rehabilitar". En este escenario, con el mismo número de viviendas totales rehabilitadas, se propone entrar las actuaciones sobre las más rentables del paquete de 7,1 millones a rehabilitar hasta 2050.

Escenario F: "Envolvente+Instalaciones con las optimizaciones $D+E$ ". Se combinan las optimizaciones de los escenarios Dy E.

Como puede verse en los gráficos de la FIG. 20, los Escenarios A (Tendencial) y B (Sólo Instalaciones) no consiguen alcanzar los objetivos energéticos planteados por el PNIEC, de manera que es necesario añadir las intervenciones sobre la envolvente. Con el Escenario C (Base) ya se pueden conseguir estos objetivos, siendo posible optimizar los resultados -manteniendo el volumen de viviendas a rehabilitar y la inversión total- mediante la aceleración del ritmo inicial y la concentración de las actuaciones sobre el parque más ineficiente. La combinación de ambas optimizaciones (Escenario F) podría llegar a mejorar los resultados acumulados en un $20 \%$ extra.

En el documento se detallan las inversiones necesarias en el período 2020-2030, totales y anuales, para poner en marcha el Escenario C, cuyo resumen se recoge en la tabla de la FIG. 21. 


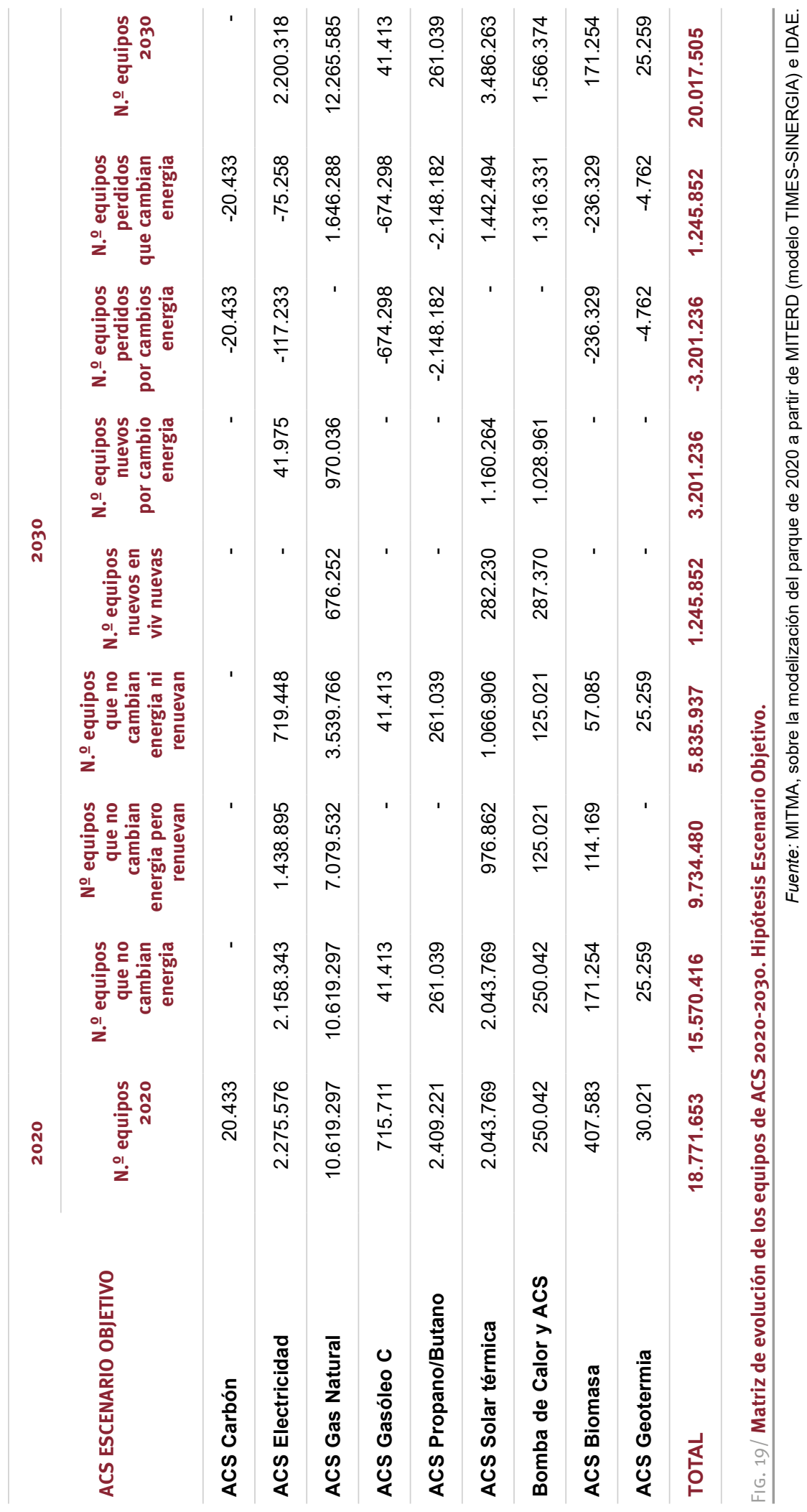



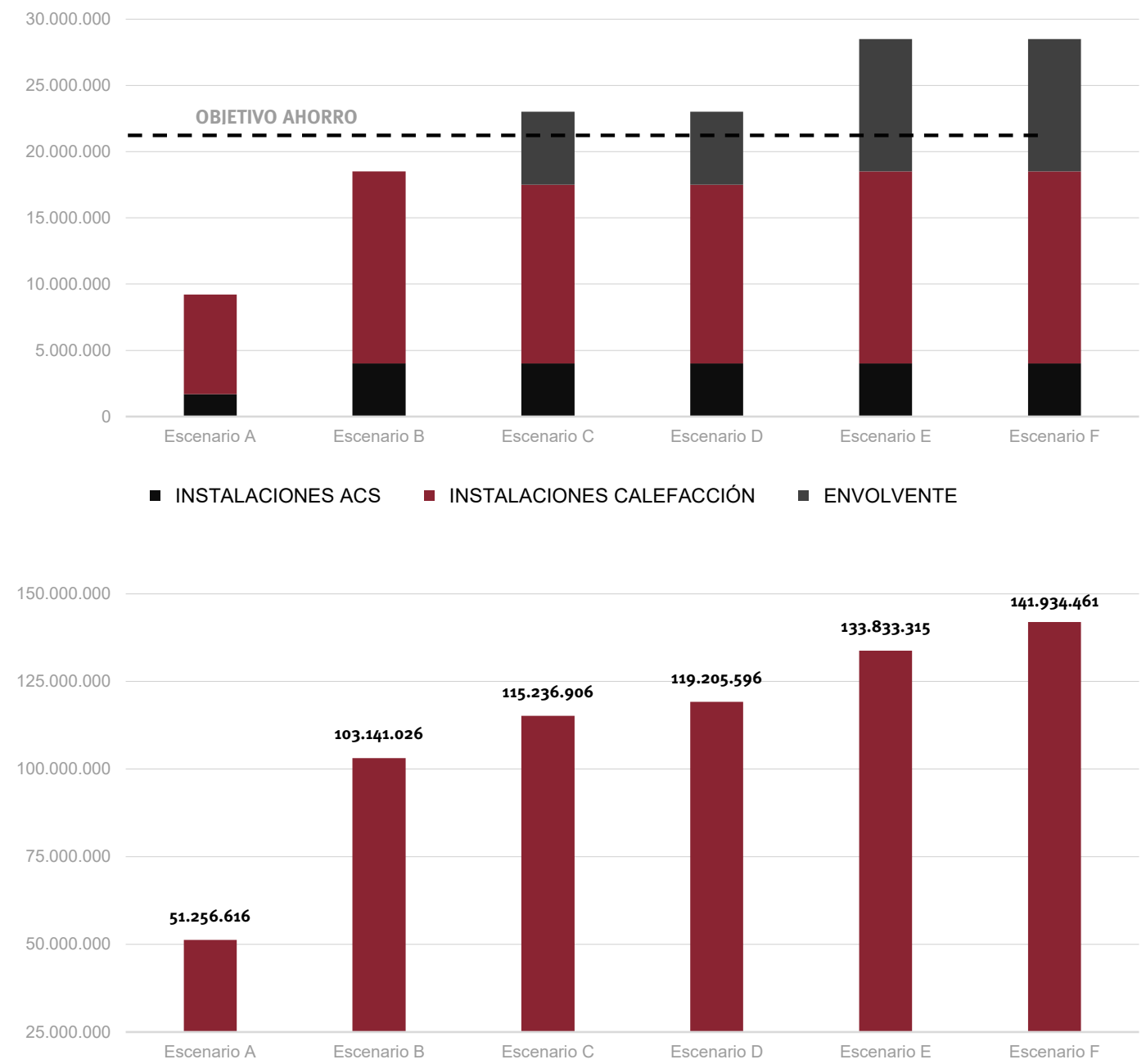

FIG. 20/ Resultados Energéticos (MWh): Ahorros totales a 2030 (arriba) y Resultados Energéticos: Ahorros anuales acumulados a 2030 (abajo).

Fuente: MITMA

En la tabla (FIG. 19) se recogen las diferentes actuaciones que este escenario contempla: renovación de equipos de ACS y de calefacción por agotamiento de su vida útil (en los que supone que las inversiones privadas a realizar entran dentro del escenario tendencial y por tanto no precisan ayudas públicas), sustitución de equipos de ACS y calefacción con cambio de combustible (en los que se supone que existe inversión pública para incentivar la consecución de los objetivos energéticos en 2030), y, finalmente, actuaciones de rehabilitación energética de la envolvente.
El volumen total de inversión necesario 20202030 sería de 41.471 millones de $€$, de los cuales 15.520 millones corresponderían a inversiones privadas (consideradas como tendenciales) para la renovación de equipos de ACS y/o calefacción por simple agotamiento de su vida útil. La inversión pública (6.946 millones de $€$ ) se destinaría a incentivar la rehabilitación de envolventes (4.389 millones), cubriendo $1 / 3$ de la inversión total necesaria, y otros 2.557 millones para la sustitución de equipos de ACS y/o calefacción con los cambios de combustible necesarios para conseguir los objetivos energéticos marcados en 2030 (cubriendo $1 / 5$ de la inversión total). 


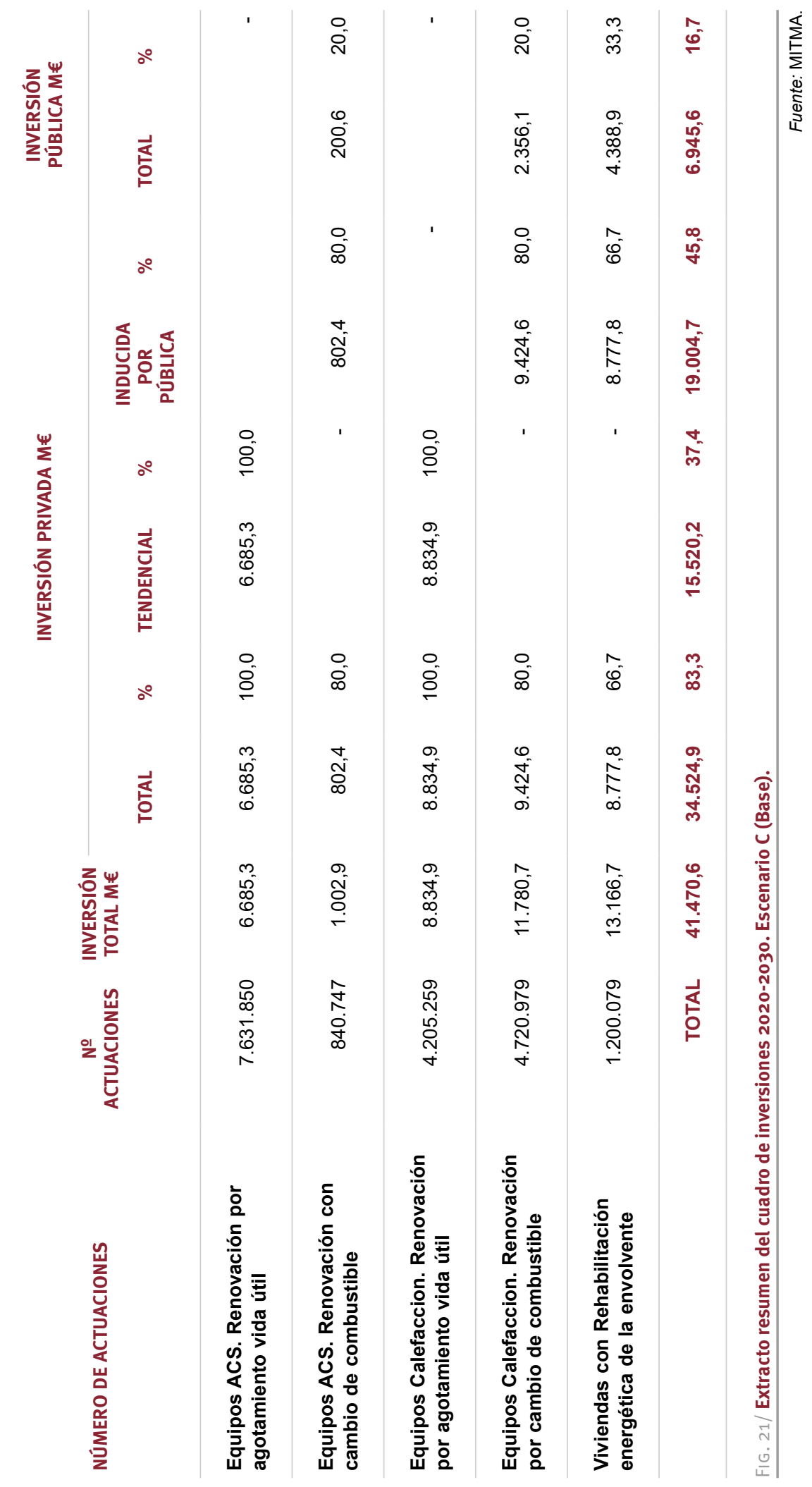




\section{Análisis micro desde la viabilidad económica desde el punto de vista del ciudadano}

Teniendo en cuenta que la financiación de las intervenciones ha sido el cuello de botella de la rehabilitación en España, y la actual crisis económica derivada de la pandemia de Covid-19, la ERESEE 2020 presta especial atención a la parte de la financiación privada que no corresponde a las inversiones tendenciales. En el escenario descrito en la tabla anterior, el volumen de financiación privada necesaria asciende a $19.004,7$ millones de $€$. De esta cantidad, corresponderían a las instalaciones $9.424,6$ millones de $€$ para financiar 4,7 millones de equipos de calefacción y 802,4 millones de $€$ para cambiar 0,84 millones de equipos de ACS que se renovarían cambiando de combustible de acuerdo con la senda energética planteada por el PNIEC y la ELP 2050. Para conseguir movilizar estas inversiones privadas, se ha considerado un volumen de financiación pública que cubriría el $20 \%$ de las inversiones totales, estimándose que esta cifra sería viable, en tanto en cuanto se trata de inversiones de una cierta entidad relativa, pero en un margen asumible (unos 2.500 $€$ de media, con ayudas en torno a $500 €$ ) y en todo caso, rápidamente amortizable mediante los ahorros obtenidos.

La cuestión más difícil correspondería pues a las inversiones en la envolvente, donde habría que movilizar $8.777,8$ millones de $€$ de inversión privada para poder rehabilitar los $1,2 \mathrm{mi}$ llones de viviendas previstos a 2030. En este caso, la inversión media por hogar rondaría los 10.000-12.000 € -aunque, como se ha visto, la inversión concreta es muy variable según la tipología edificatoria-, cifra que ya supone un desembolso importante, para la que se ha previsto una cobertura media de ayudas públicas de una tercera parte (es decir, unos 3.300-4.000 $€$ por hogar). En este caso, la financiación pública debe diseñarse a medida para ser capaz de cubrir las diferentes situaciones económicas de los hogares.

El esquema de la FIG. 22 representa estos diferentes menús de financiación, variando entre los casos en que sería necesario financiar las actuaciones al $100 \%$ con fondos públicos (correspondientes a los hogares en pobreza energética, que se analizan aparte y no entrarían en este esquema), hasta los hogares con más posibilidades económicas, que podrían realizar sin problema estas inversiones mediante recursos propios, amortizándolas a través de los ahorros energéticos obtenidos. En los casos intermedios, se contaría con toda una batería de mecanismos complementarios: plusvalías urbanísticas y ahorros energéticos capitalizados, recursos propios, subvenciones, préstamos (públicos o privados), desgravaciones fiscales, etc.

Dado que la Directiva insiste en los "enfoques rentables de rehabilitación”, la ERESEE 2020

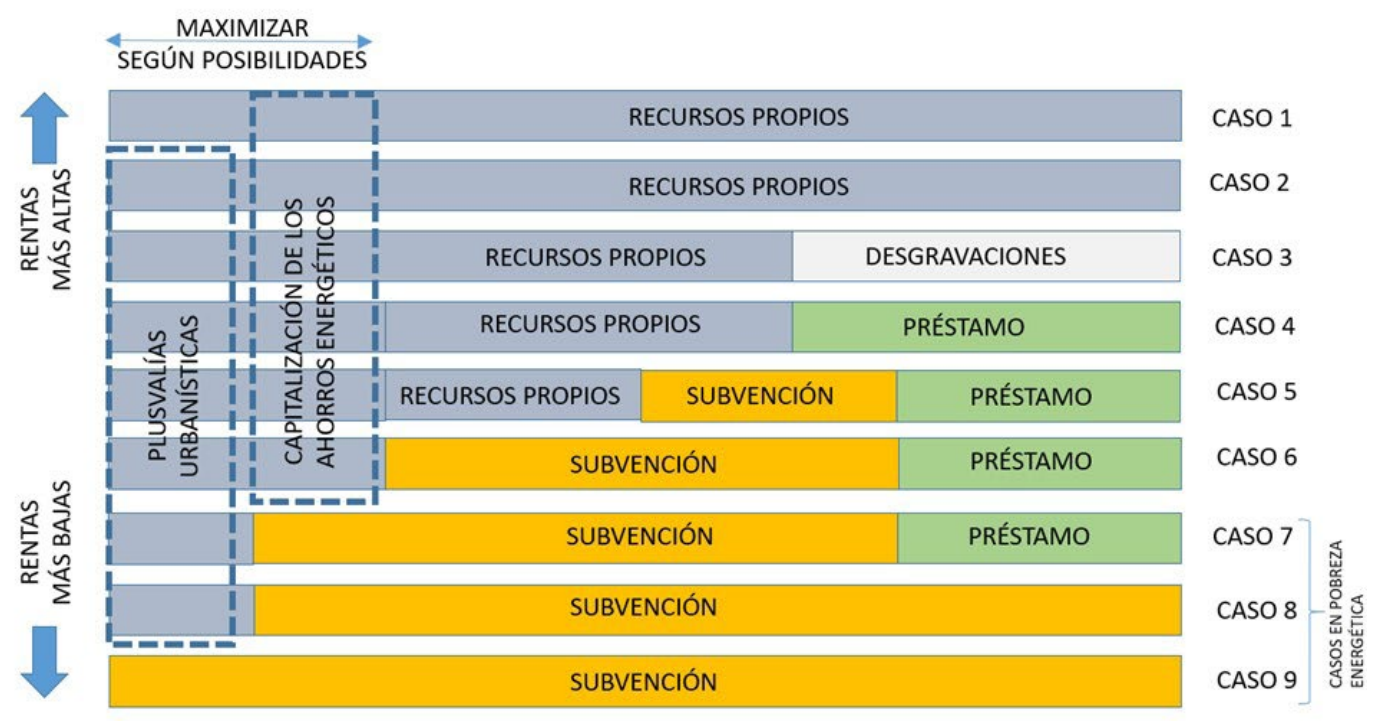

FIG. 22/ Diagrama ilustrativo de la variedad de esquemas y casos de financiación a tener en cuenta.

Fuente: MITMA. 
ha realizado el ejercicio de analizar el porcentaje del coste de las obras en la envolvente que podrían cubrirse mediante la capitalización de los ahorros energéticos en un plazo determinado. El gráfico de la FIG. 23 ilustra la distribución de las viviendas según el coste de las intervenciones sobre la envolvente (como se aprecia, mayoritariamente comprendidas entre 10.000 y $15.000 €)$ y según el porcentaje de esta inversión que podrían cubrir los ahorros energéticos obtenidos durante 15 años. Como era de esperar por el clima español, serían muy pocos los casos en que estos ahorros podrían cubrir el $100 \%$ de la inversión necesaria, como idealmente se plantea para el centro y el norte de
Europa. Sin embargo, la buena noticia es que, prácticamente en la totalidad de los casos, los ahorros pueden cubrir efectivamente entre el 20 y el $40 \%$ de los costes, llegando incluso hasta el $60 \%$ en determinadas situaciones.

Comprobada esta posibilidad, la ERESEE pasa a analizar la viabilidad de los esquemas mixtos en que se combinarían los ahorros energéticos con las ayudas públicas y otras fuentes de financiación, sin entrar a detallar estas últimas, que serían complementarias ${ }^{29}$ (FIG. 24). Lo que se comprueba, con distintos plazos -10, 15 o 20 años- es que, con ayudas públicas en torno a un tercio de la inversión total, son mayoritarios

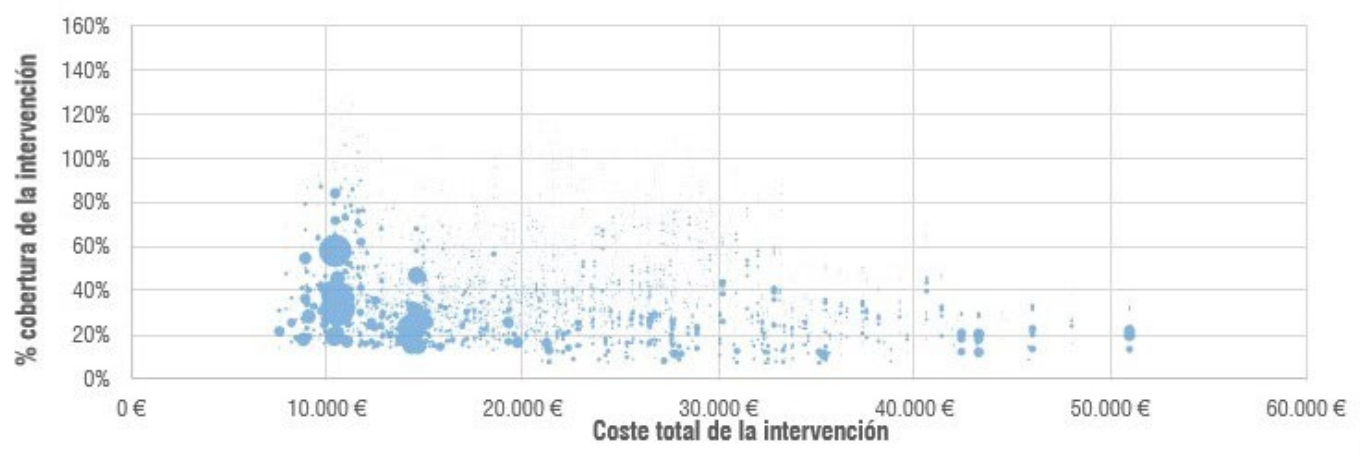

FIG. 23/ Distribución de viviendas según el porcentaje de cobertura y coste de intervención (opción a 15 años).

Fuente: Cíclica [Space, Community, Ecology] para MITMA.
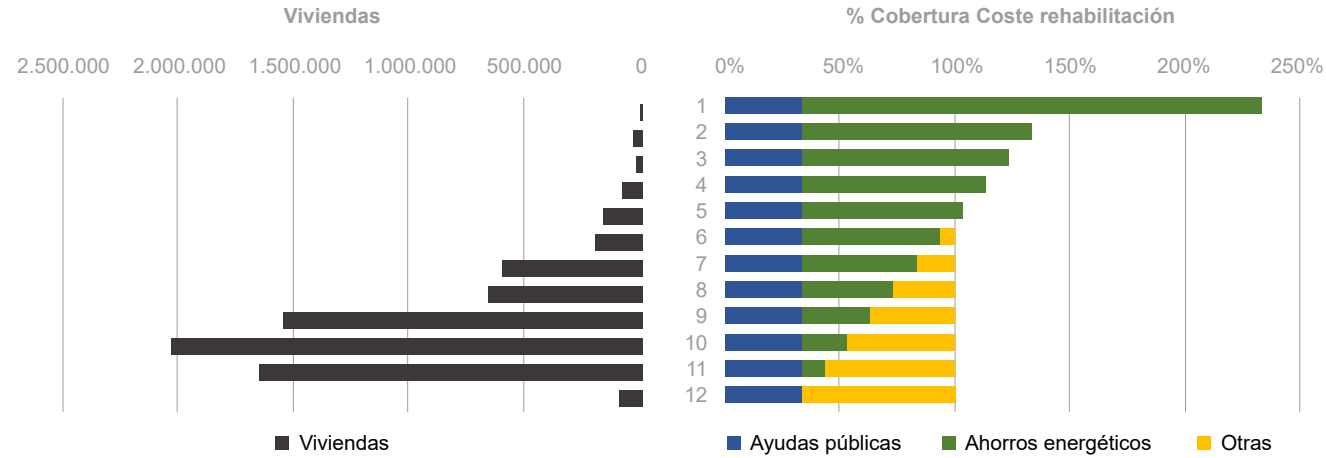

FIG. 24/ Distribución del número viviendas según el porcentaje de cobertura del coste de rehabilitación (opción a 15 años).

Fuente: Cíclica [Space, Community, Ecology] para MITMA.

${ }^{29}$ En los dos extremos podrían ser desde recursos completamente externos (como plusvalías urbanísticas que se consiguieran poner en marcha), hasta recursos propios (ahorro) de los propietarios, pasando por préstamos (públicos o privados), ayudas complementarias, etc. 
los casos en que los ahorros energéticos cubrirían otra buena parte de la inversión, de manera que la fracción restante de financiación a cubrir $^{30}$ quedaría dentro de en unos márgenes razonables.

\section{El tratamiento del problema de la Pobreza energética en la ERESEE 2020}

Una vez comprobada la viabilidad económica de los casos generales de rehabilitación planteados, la ERESEE 2020 aborda también con especial detalle los hogares en Pobreza Energética, donde no sería posible poner en juego la capitalización de ahorros, pues se parte de una situación en la que hay restricciones en el consumo como consecuencia de la situación de pobreza.

\subsection{Caracterización e identificación de las situaciones de Pobreza Energética}

La Estrategia Nacional contra la Pobreza Energética (ENPE) 2019-2024 realiza un acercamiento multidimensional a la misma, planteando 4 indicadores diferentes que abordan las múltiples dimensiones de este problema: Temperatura inadecuada en la vivienda en invierno, Retraso en el pago de facturas de suministros, Gasto desproporcionado (2M) y Pobreza Energética Escondida (HEP) a través del porcentaje de hogares cuyo gasto energético absoluto es inferior a la mitad de la mediana nacional (equivalente a M/2). De todos ellos, la ERESEE 2020 se centra en los que reflejan la ausencia de bienestar interior debido a un insuficiente gasto en climatización, pero en lugar del indicador HEP, la ERESEE va a utilizar otro indicador de Pobreza Energética Escondida (PEE), que a su vez permite incorporar el factor de la renta de los hogares. Este indicador PEE se ha desarrollado en las investigaciones realizadas al respecto por SÁNCHEZ-GUEVARA SÁNCHEZ, SANZ FERNÁNDEZ, \& HERNÁNDEZ AJA (2014), comprobándose que el PEE incluye casos de Pobreza Energética Escondida que no quedan reflejados si se usa sólo el HEP.

Además de incorporar el nivel de renta para identificar con más precisión los casos de Pobreza Energética Escondida (PEE) en la división de los grupos de hogares en función de su relación con la Pobreza Energética relacionada con el Gasto desproporcionado (2M) también se utilizan divisiones por niveles de renta, lo cual permite incorporar en el análisis un factor clave según la propia ENPE. Este análisis da como resultado la división de los hogares en los grupos que se pueden observar en la FIG. 25 y cuya descripción es la siguiente:

- Grupo 1 (G1): hogares que están bajo los indicadores de Pobreza Energética (2M) y monetaria (60\% de la mediana de la renta).
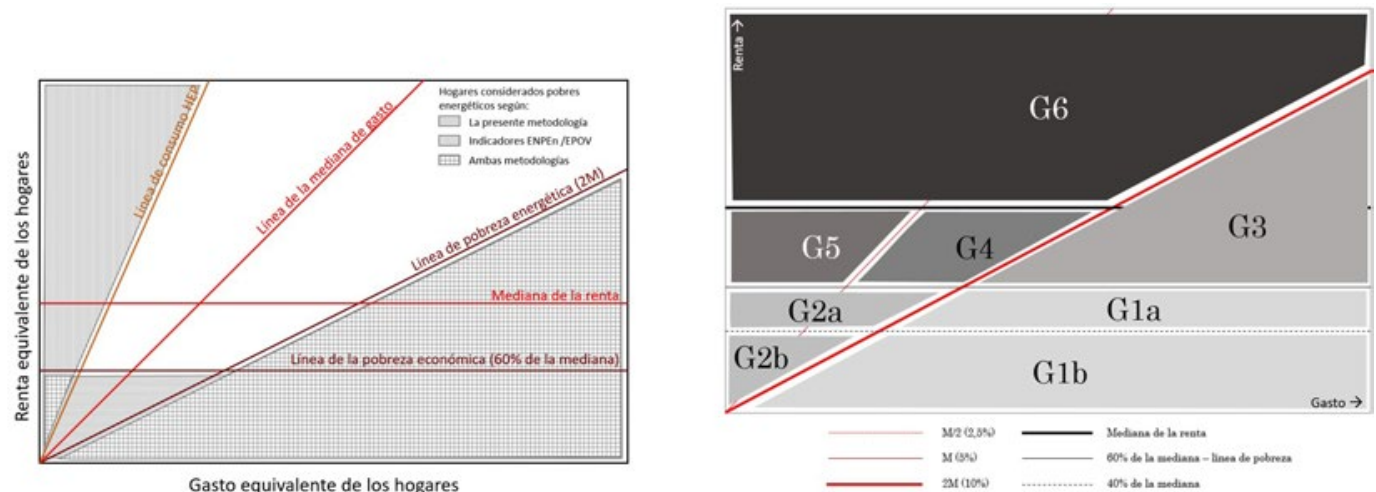

FIG. 25/ División de los grupos de hogares en función de su relación con la renta y el gasto en energía.

Fuente: SÁNCHEZ-GuEVARA C.\& SANZ FERNÁNDEZ. A (2020) a partir de la metodología desarrollada en SÁNCHEZ-GuEVARA SÁNCHEZ, SANZ FERnÁNDEZ, \& HERNÁNDEZ AJA, (2014).

\footnotetext{
30 Del modo comentado en la nota anterior.
} 
- Grupo 1a (G1a): aquellos entre el 40\% de la mediana y la línea de pobreza $(60 \%$ de la mediana).

- Grupo 1b (G1b): aquellos por debajo del $40 \%$ de la mediana.

- Grupo 2 (G2): hogares que sufren pobreza monetaria y gastan menos del $2 \mathrm{M}$ en climatización -Pobreza Energética Escondida (PEE)-

- Grupo 2a (G2a): aquellos entre el $40 \%$ de la mediana y la línea de pobreza $(60 \%$ de la mediana).

- Grupo 2b (G2b): aquellos por debajo del $40 \%$ de la mediana.

- Grupo 3 (G3): hogares en Pobreza Energética (según el indicador $2 \mathrm{M}$ ) pero sin sufrir pobreza monetaria (por encima del $60 \%$ de la mediana de la renta).

- Grupo 4 (G4): hogares vulnerables por Pobreza Energética (según el indicador $2 \mathrm{M}$ y el indicador PEE) y por pobreza monetaria (según el indicador del $60 \%$ de la mediana de la renta).

- Grupo 5 (G5): hogares vulnerables por Pobreza Energética (según el indicador PEE) y por pobreza monetaria (según el indicador del $60 \%$ de la mediana de la renta).

- Grupo 6 (G6): hogares fuera de vulnerabilidad económica y energética.

Además, se ha profundizado también en la relación entre pobreza energética y pobreza en general, analizándose las situaciones de vulnerabilidad económica en función del IPREM (Indicador Público de Renta de Efectos Múltiples) y su relación con los grupos de Pobreza Energética mencionados. El cuadro de la FIG. 26 resume los resultados obtenidos.

En relación con los hogares con vulnerabilidad económica, pero fuera de situaciones de Pobreza Energética (es decir, los hogares fuera de los grupos G1 y G3 en el cuadro anterior), y teniendo en cuenta los resultados obtenidos sobre el porcentaje de la inversión que pueden cubrir los ahorros energéticos (tomado aquí de forma conservadora, como un $25 \%$ de media), se ha diseñado un esquema progresivo de ayudas públicas matizado en función de la renta de los hogares y se ha comprobado que el importe

${ }^{31} \mathrm{El}$ coste de las medidas se ha obtenido del informe "Rehabilitación exprés para hogares vulnerables. Soluciones de total sería equivalente a la hipótesis manejada en las estimaciones anteriores de cubrición de una tercera parte. Según esta propuesta, sería posible mantener este porcentaje medio con la siguiente redistribución: en los hogares (sin Pobreza Energética) con ingresos inferiores a 1xIPREM (281.699 hogares), se financiaría el $100 \%$ de la parte no cubierta por los ahorros; en los hogares con ingresos entre 1 y $2 x 1-$ PREM (2.307.638), el 75\% de esa misma parte; en los hogares con rentas entre 2 y 3 XIPREM (3.363.296), el 50\%; y, finalmente, en los que tengan más de 3xIPREM (9.996.335), el $20 \%$.

\subsection{Propuestas de intervención para combatir la Pobreza Energética}

Aplicando las consideraciones anteriores, la ERESEE 2020 finalmente identifica y territorializa 2.572.361 viviendas en situación de Pobreza Energética sobre las que plantea una serie de medidas de rehabilitación energética mediante dos tipos de soluciones: actuaciones dirigidas a la sustitución de equipos de climatización por otros más eficientes energéticamente (en línea con la Medida 9 de la ENPE) y medidas pasivas de intervención sobre la envolvente (huecos, fachada y cubierta), en línea con lo establecido en las Medidas 10 y 11 de la ENPE.

Para establecer los menús de intervención en hogares en Pobreza Energética y adaptarlos a cada caso se tienen en cuenta la zona climática de la provincia (simplificada, siguiendo las zonas de SPAHOUSEC, en atlántica, continental y mediterránea), la tipología (unifamiliar o plurifamiliar), el tamaño del municipio (urbano o rural), la estimación de características geométricas en base al Censo de vivienda de 2011 (superficies de fachada, de cubierta, de solera y acristalada) y el coste de las medidas a implementar ${ }^{31}$. Los menús de intervención propuestos son los siguientes:

- Menú de intervención en edificios plurifamiliares por el exterior.

- Menú de intervención en edificios plurifamiliares por el interior.

- Menú de intervención parcial en edificios unifamiliares.

- Menú de intervención completa en edificios unifamiliares.

bajo coste" (De Luxán \& al., 2017) https://www.fundacionnaturgy.org/rehabilitacion-viviendas-colectivos-vulnerables/ 


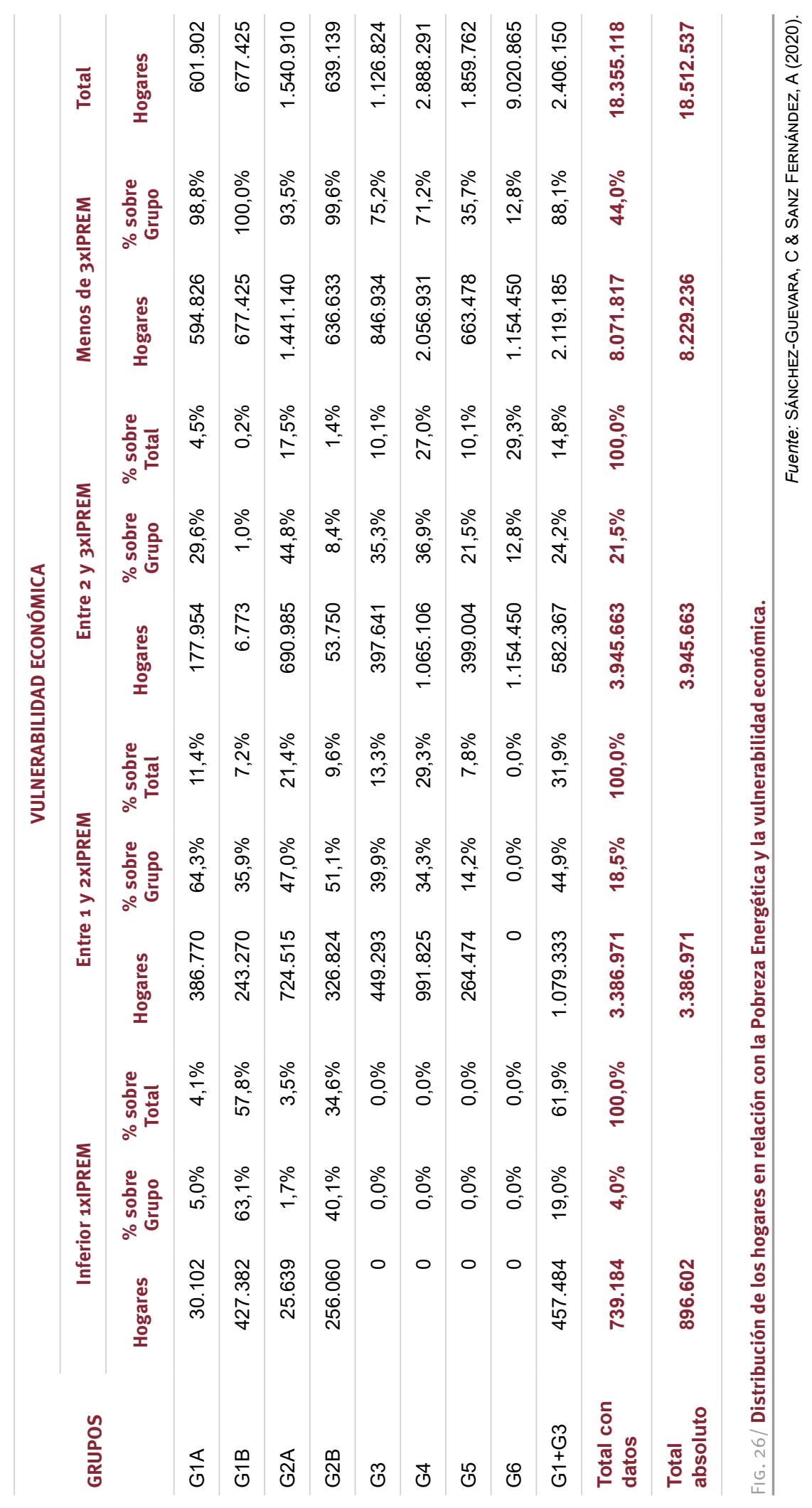


- Medidas exprés: micromejoras y reparaciones.

- Medidas activas sobre las instalaciones.

Finalmente, se plantean dos escenarios: uno que contiene exclusivamente medidas activas sobre las instalaciones y otro que combina éstas con medidas pasivas sobre la envolvente. En este segundo escenario, se plantea aplicar alguno de los citados menús de rehabilitación de la envolvente en 317.490 viviendas, con unos ahorros de $230.712 \mathrm{MWh}$ y un coste total de 2.181 millones de $€$, de las cuales casi el $60 \%$ corresponderían a plurifamiliares y el $40 \%$ a unifamiliares, siendo el tipo de intervención más frecuente el menú de intervención por el exterior en plurifamiliares $(37,7 \%)$, seguido por el de actuación parcial en la envolvente de las unifamiliares $(30,3 \%)$, el menú de actuación por el interior en plurifamiliares vivienda a vivienda $(21,9 \%)$ y, finalmente, con el $10,1 \%$, el menú de intervención completa en unifamiliares.

Combinando la rehabilitación de la envolvente y las instalaciones, los ahorros energéticos totales ascenderían a 1.381.086 MWh, y el coste a 5.048 millones de $€$ (2.181 millones de la envolvente y 2.866 de las instalaciones). Una vez calculado este coste total, se diseña un escenario de cubrición gradual de las necesidades de financiación de acuerdo con la renta del hogar, cubriéndose el $100 \%$ del coste para los hogares en Pobreza Energética con ingresos inferiores a 1 vez el IPREM, el $75 \%$ del coste para los hogares entre 1 y 2 veces el IPREM, el $50 \%$ para hogares entre 2 y 3 veces el IPREM y el $20 \%$ para hogares con más de 3 veces el IPREM. Con estas hipótesis, la necesidad de financiación pública ascendería a un total de 3.389 millones de $€$, distribuidos según se especifica en el cuadro de la FIG. 27, por hogares según tramos del IPREM.

\section{Análisis macroeconómico: Impactos en el PIB, el empleo, las cuentas Administraciones Públicas, etc}

Además del análisis microeconómico desde el punto de vista de la viabilidad para el ciudadano de las actuaciones propuestas, la ERESEE 2020 también estudia la viabilidad macroeconómica y el impacto de las inversiones previstas en la economía y en los presupuestos de las Administraciones Públicas.

El análisis del impacto macroeconómico de la ERESEE ha sido realizado por el Basque Centre for Climate Change (BC3) $)^{32}$ para MITMA. Se ha utilizado el modelo económico $\mathrm{DENIO}^{33}$, que ha sido también empleado en el análisis de los impactos del PNIEC 2021-2030, siendo por tanto ambos análisis coherentes entre sí.

En la FIG. 28 se muestra el efecto de la política de rehabilitación energética en edificios del sector residencial sobre el PIB nacional. El impacto sobre la economía sería positivo en todo el periodo, generando un impulso económico de entre 2.339 y $6.517 \mathrm{M} €$ adicionales entre 2021 y 2030 , es decir, una contribución adicional del 0,44\% al PIB nacional en 2030. Además, los ahorros en la factura energética debidos al efecto conjunto de la rehabilitación de la envolvente térmica y la sustitución de instalaciones térmicas por otras más eficientes supondrían un ahorro de 1.690 M€ en el año 2030 y un ahorro acumulado de 7.730 M€ en todo el periodo analizado.

El efecto sobre el empleo también es muy positivo en todo el periodo, estimándose que se crearían entre 32.000 y 85.000 nuevos puestos de trabajo anuales entre 2021 y 2030 . Como puede

\begin{tabular}{lccccc}
\hline & $\begin{array}{c}\text { Inferior 1X } \\
\text { IPREM }\end{array}$ & $\begin{array}{c}\text { Entre 1 y 2x } \\
\text { IPREM }\end{array}$ & $\begin{array}{c}\text { Entre } \mathbf{2} \text { y 3x } \\
\text { IPREM }\end{array}$ & $\begin{array}{c}\text { Más de 3x } \\
\text { IPREM }\end{array}$ & $\begin{array}{c}\text { TOTAL } \\
\text { Millones de } € \text { Totales }\end{array}$ \\
\hline 959,8 & $2.264,3$ & $1.221,7$ & 602,0 & $5.047,8$ \\
\hline Millones de $€$ Inversión Pública & 959,8 & $1.698,2$ & 610,9 & 120,4 & $3.389,3$ \\
\hline
\end{tabular}

FIG. 27 / Distribución de la financiación según el tipo de hogares en Pobreza Energética por IPREM (millones de €). Escenario 2.

\footnotetext{
${ }^{32}$ Basque Centre for Climate Change (BC3) (2020): “Impacto económico de la rehabilitación energética de viviendas en España en el periodo 2021-2030".

https://www.mitma.gob.es/el-ministerio/planes-estrategicos/ estrategia-a-largo-plazo-para-la-rehabilitacion-energetica-enel-sector-de-la-edificacion-en-espana

33 DENIO es un modelo Econométrico Dinámico InputOutput de la economía española, que tiene su origen en el modelo FIDELIO del Joint Research Centre (JRC) de la
}

Comisión Europea. El modelo ha sido desarrollado por el Basque Centre for Climate Change (BC3) en colaboración con el Centre of Economic Scenario Analysis and Research (CESAR). Este modelo permite simular el efecto de un amplio abanico de políticas económicas, fiscales, energéticas o ambientales. Además, el modelo ha sido estimado econométricamente con los últimos datos disponibles del Instituto Nacional de Estadística (INE), del Banco de España y de EUROSTAT. 


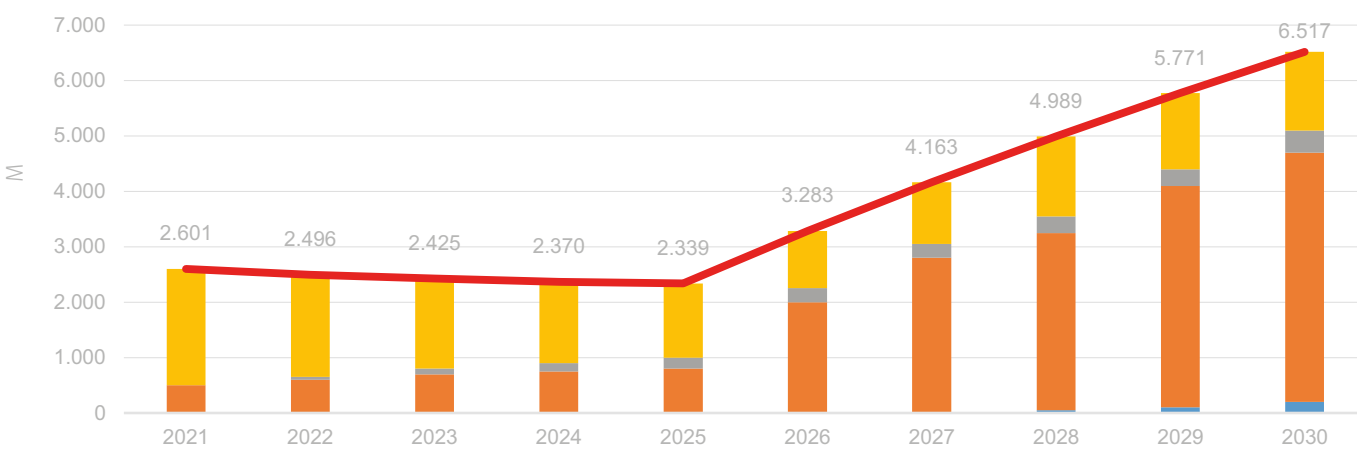

Env. Térmica: Factura Energética $\quad$ Env. Térmica Inversión $\quad$ Sut. Inst Térmicas: Factura Energética $\square$ Sut. Inst. Térmicas: Inversión

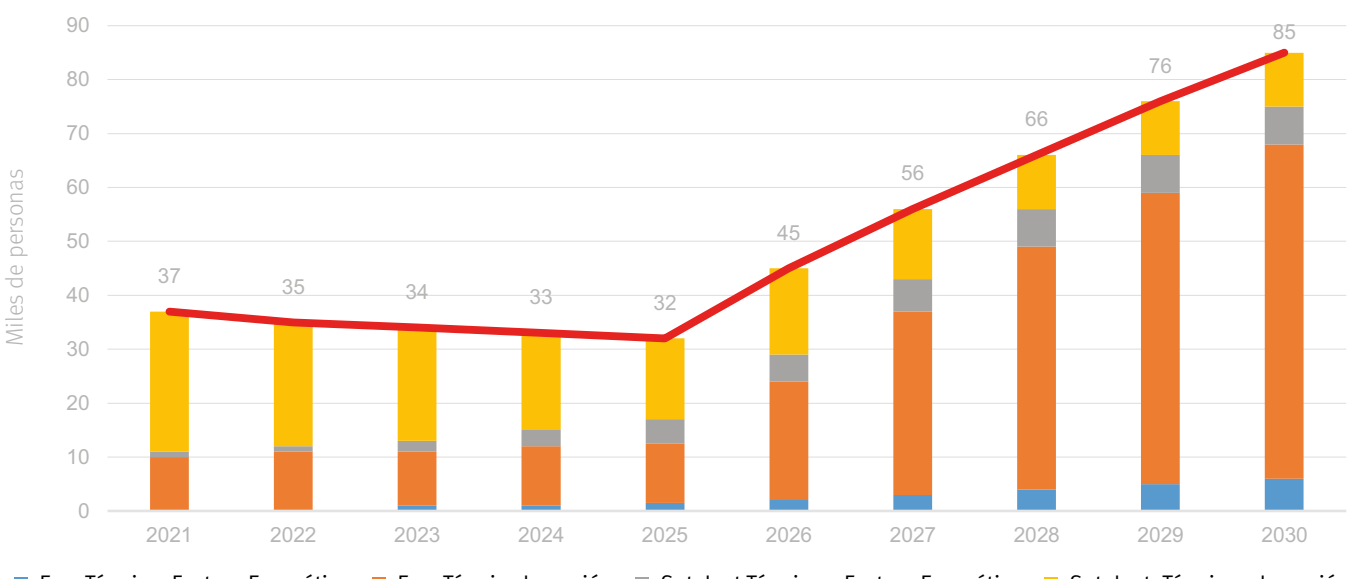

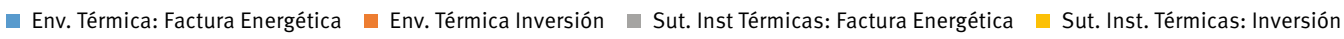

FIG. 28/ Arriba: Variación en el PIB (M€) en el periodo 2021-2030. Abajo: Variación en el empleo (miles de personas) en el periodo 2021-2030.

Fuente: Basque Centre for Climate Change (BC3) para MITMA.

verse en los gráficos, los resultados de contribución al PIB y empleo son especialmente significativos en la segunda mitad de la década, en paralelo al ritmo previsto en el número de viviendas rehabilitadas por el PNIEC (Escenario $C$ de la ERESEE), pudiéndose mejorar notablemente si se consiguiera adelantar el ritmo en la primera parte de la década, aun manteniendo el volumen total de viviendas a rehabilitar (Escenarios D y F).

En la figura inferior se recoge el impacto en las cuentas de las AA.PP. por el lado de los ingresos, mostrando que los efectos netos sobre la recaudación serian positivos a lo largo de todo el periodo. En este sentido, aunque se reducirían

\footnotetext{
${ }^{34}$ La modelización se ha realizado bajo el supuesto de la existencia de saldo presupuestario equilibrado entre los ingresos y gastos de la administración pública con el objetivo de simplificar el análisis. Es importante destacar que el aumento del gasto público es exclusivamente fruto del impacto
}

los ingresos de algunos impuestos - como los de la energía-, el volumen total se vería sobradamente compensado por el aumento de la recaudación mediante otras vías impositivas. En particular, los impuestos sobre la renta, patrimonio y capital aumentarían entre 491 M€ y 2.231 M€ y las contribuciones a la Seguridad Social entre $276 \mathrm{M} €$ y $1.058 \mathrm{M} €$ en toda la década. De este modo, los ingresos de las AA.PP. cubrirían holgadamente la financiación pública necesaria para poner en marcha las políticas de rehabilitación energética planteadas durante todo el periodo 2021-2030. El resto de recaudación fiscal, unos 15.116 M€, se podría destinar a otros usos o gastos de la AA.PP. ${ }^{34}$.

económico inducido por la política de rehabilitación de la envolvente térmica, ya que, se ha supuesto que las ayudas públicas a la rehabilitación son compensadas con una reducción en otras partidas. 
Finalmente, también hay que destacar que la política propuesta tendría un impacto progresivo beneficioso para los hogares más vulnerables, pues si bien consumo aumentaría en todos los tipos de hogares, lo haría aún en mayor medida en los hogares de menor renta (aumentaría un $1,63 \%$ para los hogares del quintil 1 de renta y $1,46 \%$ para los hogares del quintil 2 de renta en el año 2030).

\section{Propuesta de medidas y aspectos clave a destacar: el triángulo de la rehabilitación}

Para finalizar, la ERESEE 2020 propone una completa batería de medidas organizadas en torno a 11 ejes temáticos, que son los siguientes: 1. Eje estructurante: impulso de la coordinación sectorial, vertical y horizontal; 2. Desarrollo normativo y medidas administrativas a favor de la rehabilitación energética; 3 . Rehabilitación de los edificios de las administraciones Públicas y otras medidas ejemplarizantes; 4. Medidas de financiación pública; 5 . Medidas para el fomento y movilización de la financiación privada; 6 . Lucha contra la Pobreza Energética; 7. Medidas para el despliegue de un nuevo modelo energético en el sector de la rehabilitación; 8. Medidas para la activación y agregación de la demanda; 9. Medidas desde el lado de la oferta: profesionalización, modernización del sector de la rehabilitación, formación y capacitación; 10. Información y sociedad: el ciudadano en el centro; y 11. Eje transversal: Desarrollo de estadísticas, indicadores y seguimiento.

En cuanto a la financiación, que en el diagnóstico se destacaba como uno de los cuellos de botella más importantes, hay que resaltar como novedad el anuncio de la próxima llegada de una partida muy relevante de fondos europeos para ayudar a reparar los daños económicos y sociales causados por la pandemia de coronavirus, sentando al mismo tiempo las bases para una Europa más moderna y sostenible. En este sentido, el pasado 7 de octubre de 2020, el Presidente del Gobierno español presentó las líneas generales del Plan de Recuperación, Transformación y Resiliencia, que guiará la ejecución de 72.000 millones de euros de fondos europeos hasta 2023. En él se establecen 10 "políticas palanca de reforma estructural para un crecimiento sostenible e inclusivo", siendo la primera la "Agenda Urbana y Rural y lucha contra la despoblación", dotada con el $16 \%$ de los recursos y dentro de la cual se incluye un "Plan de Rehabilitación de Vivienda y Regeneración Urbana", que es de esperar, esté perfectamente alineado con la ERSEE 2020.

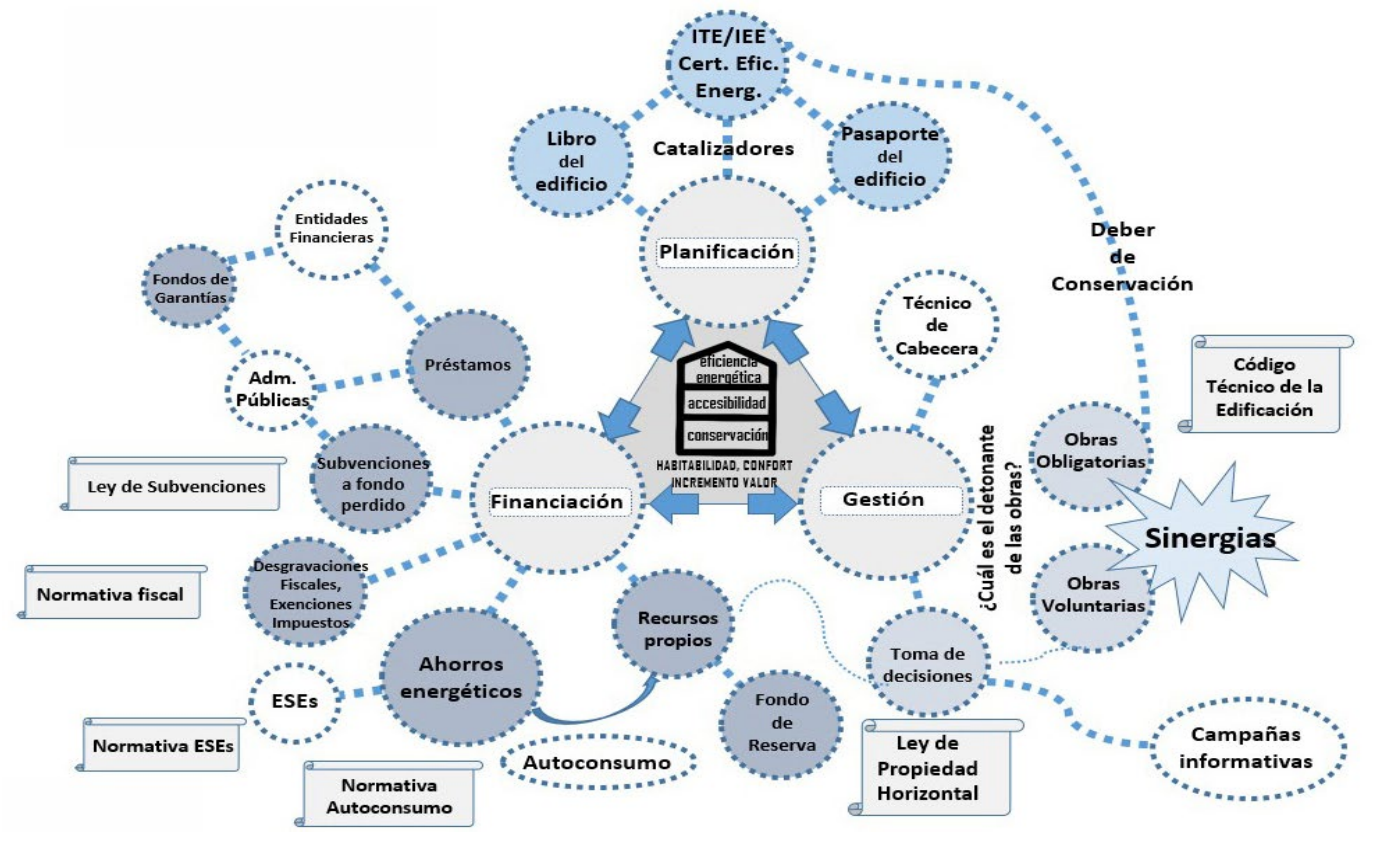

FIG. 29/ El triángulo de la rehabilitación a escala del edificio.

Fuente: MITMA. 

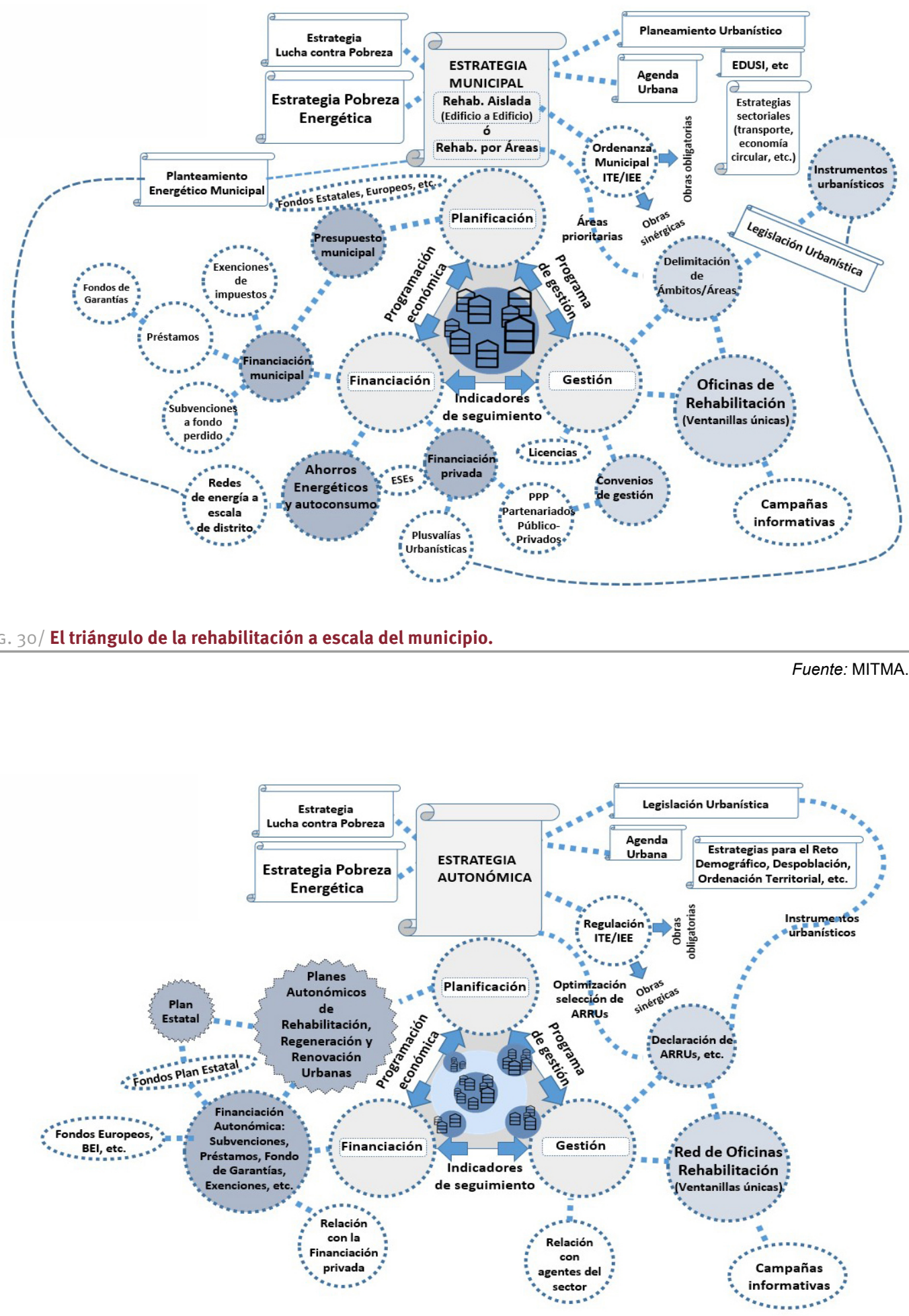
Además, la ERESEE 2020 ha destacado cómo es necesario abordar las medidas planteadas desde una perspectiva integrada. En los esquemas de las FIGs. 29, 30 y 31 se propone una lectura de las interrelaciones entre los principales factores que inciden en la rehabilitación desde la escala del edificio, desde la perspectiva municipal y desde la autonómica, a partir de los 3 elementos clave - planificación, gestión, financiación- que configuran el "triángulo" de la rehabilitación. Es necesaria la correcta articulación entre estos 3 elementos clave, así como entre las 3 escalas para que la rehabilitación pueda desplegar efectivamente todo su potencial y contribuir así a la transformación del sector de la edificación en España durante los próximos años.

\section{Bibliografía}

Arcas-AbelLA, K. \& al. (2018): "Aproximación a la demanda energética residencial para calefacción en España. Estudio (02) para la ERESEE 2020 "Estrategia a largo plazo para la Rehabilitación Energética en el Sector de la Edificación en España". Accesible en:

https://cdn.mitma.gob.es/portal-web-drupal/ planes estartegicos/2 2020 aproximacion demanda residencial.pdf

ATECYR (2019): "Informe sobre prospectiva $y$ evolución futura de los sistemas de climatización y ACS en la edificación residencial".

https://cdn.mitma.gob.es/portal-web-drupal/planes estartegicos/4 2020 sistemas climatizacion y acs residencial.pdf

Castellazzi, L. \& Zangheri P. \& Paci, D. (2016): "Synthesis Report on the assessment of Member State's Building Renovation Strategies"; Accesible en: https://ec.europa.eu/jrc/en/publication/eur-scientific-and-technical-research-reports/synthesis-reportassessment-member-states-building-renovationstrategies

CASTELLAZZI L. \& al. (2019): "Assessment of second long-term renovation strategies under the Energy Efficiency Directive", EUR 29605 EN, Publications Office of the European Union, Luxembourg, 2019. Accesible en:

https://publications.jrc.ec.europa.eu/repository/ bitstream/JRC114200/kina29605enn.pdf

Cuchí, A. \& ARCAS, K.; \& PAgÉs-Ramón, A. (2017): "Estudio de distribución del consumo energético residencial para calefacción en España". Accesible en:

https://www.mitma.gob.es/recursos mfom/paginabasica/recursos/201804 estudio distribucion consumo energetico res.pdf

DE SANTIAGo RodRíGUEZ, Eduardo (2019): "Segmentación en clústeres tipológicos y caracterización geométrica del parque residencial de viviendas en España". Estudio (01) para la ERESEE 2020 "Estrategia a largo plazo para la Rehabilitación Energética en el Sector de la Edificación en España". Accesible en:

https://cdn.mitma.gob.es/portal-web-drupal/ planes estartegicos/1 2020 segmentacion parque residencial clusteres.pdf

GBCe Green Building Council España (2020): "Presentación de Conclusiones del Proceso Participativo \#ERESEE2020: Documento de observaciones y propuestas resultantes del proceso de participación pública para la actualización de la Estrategia a largo plazo para la Rehabilitación Energética en el Sector de la Edificación en España (ERESEE 2020)".

https://gbce.es/wp-content/uploads/2020/06/ Proceso-participativo-ERESEE2020 Conclusiones-Obs-y-Prop.pdf

SÁNCHEZ-GUEVARA SÁNCHEZ, C. \& SANZ FERNÁNDEZ, A. \& HERNÁNDEZ AJA, A. (2014): "Income, energy expenditure and housing in Madrid: retrofitting policy implications", Building Research \& Information. 3218 (2014) 1e13.

https://doi.org/10.1080/09613218.2014.984573

\section{Listado de acrónimos/siglas}

ACS:

CTE:

ERESEE:

GEl:

GBCe:

IDAE:

ktep:

MITMA:

MITERD:

PNAEE:

PNIEC:

UE:
Agua Caliente Sanitaria. Código Técnico de la Edificación. Estrategia de Rehabilitación Energética en el Sector de la Edificación en España. Gases Efecto Invernadero.

Green Building Council España. Instituto para la Diversificación y Ahorro de la Energía.

kilotonelada equivalente de petróleo (en inglés ktoe).

Ministerio de Transportes, Movilidad y Agenda Urbana.

Ministerio para la Transición Ecológica y el Reto Demográfico.

Plan Nacional de Ahorro y Eficiencia Energética.

Plan Nacional Integrado de Energía y Clima.

Unión Europea. 